\title{
大黄酸-氨基酸缀合物的合成及初步抗肿瘤活性研究
}

\author{
周昌健 ${ }^{a}$ 谢建伟 $*, a$ 张洁 $*, a$ 代 斌 ${ }^{a}$ \\ ( ${ }^{a}$ 石河子大学化学化工学院 新疆兵团化工绿色过程重点实验室-省部共建国家重点实验室培育基地 \\ 石河子 832003)
}

\begin{abstract}
摘要 以大黄酸为原料, 经过酯化、醚化、水解、缩合等步骤, 合成了 20 个大黄酸-氨基酸缀合物. 所有目标化合物经 ${ }^{1} \mathrm{H}$ NMR, ${ }^{13} \mathrm{C}$ NMR 和 HRMS 进行结构确证. 以顺铂和阿霉素为阳性对照药, 采用四甲基偶氮唑盐(MTT)法考察了目标 化合物体外抗肿瘤(Hela, MCF-7, HepG2, KB 和 HEK293T 等 5 株细胞)活性. 结果显示 2-(4,5-双(芐氧基)-9,10-葱醌-2甲酰氨基)-4-甲基戊酸钠(6eb) 显示出较好的抗肿瘤活性，DNA 对 2-(4,5-二丁氧基-9,10-葱醌-2-甲酰氨基)-4-甲基戊酸钠 $(\mathbf{6 d b})$ 和 $6 \mathrm{eb}$ 作用的苂光光谱均表现出苂光猝灭现象, 推测 $6 \mathrm{db}$ 可能仅是静电结合或分子部分嵌入 DNA.
\end{abstract}

关键词 大黄酸; 氨基酸; 抗肿瘤; 构效关系

\section{Study on the Synthesis and Anti-tumor Activities of Rhein-Amino Acid Conjugates}

\author{
Zhou, Changjian $^{a}$ \\ Xie, Jianwei*,a \\ Zhang, Jie ${ }^{*, a}$ \\ Dai, $\operatorname{Bin}^{a}$ \\ ( ${ }^{a}$ School of Chemistry and Chemical Engineering and Key Laboratory for Green Processing of Chemical Engineering of Xin- \\ jiang Bingtuan, Shihezi University, Shihezi 832003)
}

\begin{abstract}
20 novel rhein-amino acid conjugates were designed and synthesized from the rhein via esterification, etherification, hydrolysis, condensation and salification. Their structures were confirmed by ${ }^{1} \mathrm{H} N M R,{ }^{13} \mathrm{C}$ NMR and HRMS. All the target compounds were tested for cytotoxic activity against five cancer cell lines including Hela, MCF-7, HepG2, KB and HEK293T by methyl thiazolyl tetrazolium (MTT) method in vitro. The results showed that sodium (4,5-bis(benzyloxy)-9,10dioxo-9,10-dihydroanthracene-2-carbonyl)leucinate (6eb) demonstrated moderate cytotoxic activities $\left(\mathrm{IC}_{50}<50 \mu \mathrm{mol} \cdot \mathrm{L}^{-1}\right)$. The fluorescence of compounds sodium (4,5-dibutoxy-9,10-dioxo-9,10-dihydroanthracene-2-carbonyl)leucinate (6db) and 6eb could be both quenched by DNA. It was speculated that compound $\mathbf{6 d b}$ interacted with DNA by the static attraction or was partially embedded into DNA.
\end{abstract}

Keywords rhein; amino acid; antitumor activity; structure-activity relationships

癌症是当今威胁人类生命健康的重要疾病之一. 全 球癌症研究所发布的报告表明, 整个亚洲死于癌症的人 数约占癌症死亡总人数 $55 \%{ }^{[1]}$. 近年来, 植物来源的大 量活性天然组分是发现抗肿瘤创新药的重要途径. Newman 等 ${ }^{[2]}$ 调研发现 20 世纪 80 年代后 26 年间全球推 出的药物小分子新化学实体中, 超过百分之六十的药物 小分子可追溯到天然产物激发的灵感或者天然产物本 身.

大黄酸是大黄的有效成分和标志性成分, 属于羟基 萝醌类衍生物, 具有抗炎、抗病毒、降糖调脂等广泛的 药理活性 ${ }^{[3 \sim 9]}$. 更为重要的是, 大黄酸还具有优良的抗 肿瘤活性 ${ }^{[10 \sim 14]}$ 及在协同抗肿瘤方面表现突出 ${ }^{[15,16]}$, 并
且其引起的泻下作用在人体忍受范围内. 众多的文献报 道表明, 葱醌衍生物在抗肿瘤药物研究方面 ${ }^{[17 ~ 20]}$ 应用 广泛, 以蒽醌结构作为药效团的药物已经成为一类重要 的临床抗癌药物, 如阿霉素(Doxorubicin)、米托萝醌 (Mitoxantrone)等(图 1). 阿霉素主要通过影响拓扑异构 酶 II (topoisomerase, TOPO II)的活性而发挥抗肿瘤作用; 而米托萝醌是 DNA 嵌入剂, 它能嵌入到 DNA 碱基之 间, 导致 DNA 链的胶连和链结构的破坏, 从而阻断 DNA 合成与转录; 它还能够抑制 DNA 拓扑异构酶 II, 导致基因组 DNA 的解旋. 因此, 大黄酸可作为一种潜 在的抗肿瘤药物先导物.

目前, 对于大黄酸的研究, 主要集中在其药理活性

*Corresponding authors. E-mail: cesxjw@foxmail.com; zhangjie-xj@163.com

Received July 12, 2016; revised August 20, 2016; published online September 12, 2016. 


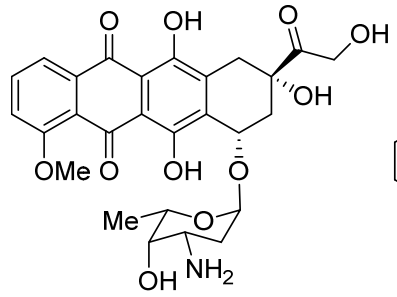

阿霉素(Doxorubicin)<smiles>O=C1c2c(O)ccc(O)c2C(=O)c2c(NCCNCCO)ccc(NCCNCCO)c21</smiles>

米托萝醌(Mitoxantrone)<smiles>O=C(O)c1cc(O)c2c(c1)C(=O)c1cccc(O)c1C2=O</smiles>

大黄酸(Rhein)

图 1 阿霉素、米托葱醌和大黄酸的化学结构

Figure 1 Chemical structures of doxorubicin, mitoxantrone and rhein

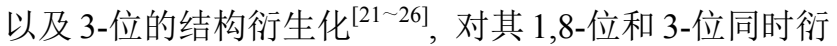
生化的研究很少. 本文围绕大黄酸 1,8-位进行衍生化的 同时，将氨基酸片段引入到大黄酸的羧基位中，重点研 究不同氨基酸取代及不同长度的烷基取代衍生物的抗 肿瘤活性及其与 DNA 作用能力，期望能够增强该系列 药物的溶解性并缓解药物的细胞毒性，提高其生物利用 率.

\section{1 结果与讨论}

\section{1 化合物合成与结构}

如 Scheme 1 所示, 本实验以大黄酸(1)为起始原料, $\mathrm{SOCl}_{2}$ 作为催化剂, 先与乙醇在回流条件下发生酯化反 应，得到大黄酸乙酯 $2 ; \mathbf{2}$ 与不同卤代烃在强碱 $\mathrm{NaH}$ 作用 下生成醚，再酯水解，得到 1,8 -二烷氧基大黄酸 $\mathbf{3 a} \sim \mathbf{3 e}$; 在 EDCI/DMAP 条件下, $\mathbf{3 a} \sim 3 \mathrm{e}$ 与不同氨基酸酯发生缩 合, 得到化合物 $\mathbf{4 a a} \sim \mathbf{4 e d}$; 在氢氧化钠作用下, 氨基酸
酯水解，得化合物 $5 \mathbf{a a} \sim \mathbf{5 e d}$; 为了增加化合物的水溶 性，最后将 5aa $\sim 5$ ed 与等物质的量的 $\mathrm{NaOH}$ 反应转化 成相应的钠盐 $6 \mathbf{a a} \sim \mathbf{6 e d}$. 目标化合物结构经 ${ }^{1} \mathrm{H}$ NMR, ${ }^{13} \mathrm{C}$ NMR 和 HRMS 进行结构确证.

\section{2 生物活性-结构分析}

实验采用四甲基偶氮唑盐(MTT)比色法对目标化合 物 6aa 6ed 进行了体外抗肿瘤活性测试, 以顺铂和阿 霉素作为阳性对照. 结果如表 1 所示, 当 C-1,8 位为甲氧 基和乙氧基时，所有衍生物整体上并未表现出明显的抗 肿瘤活性. 当 C-1,8 位为丙氧基和丁氧基, C-3 位氨基酸 残基为亮氨酸和苯丙氨酸时, 所有衍生物的抗肿瘤活性 与甲氧基和乙氧基系列相比都有所提高, 其中 $\mathbf{6 c b}$ 和 6db 活性最好, 均优于同系列其他化合物. 当 C-1,8 位为 苄氧基时，所有衍生物的抗肿瘤活性进一步提高，并且 整个系列对所测的 5 个细胞株表现出普遍的抑制活性, 其中 6eb 对所测试的 5 个细胞株均表现出显著的抑制活 性 $\left(\mathrm{IC}_{50}<50 \mu \mathrm{mol} / \mathrm{L}\right)$ ，也是所有测试化合物中抗肿瘤活 性最强的化合物. 综上可知, C-1,8 位随着基团链的增长 或体积增加，抗肿瘤活性成递增趋势，具体顺序为: 茮 氧基 $>$ 丁氧基 $>$ 丙氧基 $>$ 乙氧基 $>$ 甲氧基; $\mathrm{C}-3$ 位氨基 酸残基种类对活性的影响顺序为: 亮氨酸 $>$ 苯丙氨酸 $>$ 蛋氨酸 $>$ 甘氨酸.

\section{3 与 DNA 的相互作用}

与 DNA 的相互作用是抗肿瘤药物设计中一个重要 靶点, 我们合成的化合物初步抗肿瘤活性结果基本达到 预期设计目标，通过选择有代表性的化合物与 DNA 作 用，希望可以判断抗肿瘤活性的原因所在.

由于化合物 $6 \mathrm{db}$ 和 $6 \mathrm{eb}$ 含有共同的萝醌环作为苂光 发射基团，我们比较了 DNA 对 $6 \mathrm{db}$ 和 $6 \mathrm{eb}$ 苂光光谱的 影响(图 2). 随着 DNA 浓度的增加，两个体系均出现不<smiles>CC(C)CC(=O)c1cc(O)c2c(c1)C(=O)c1cc(C(=O)O)cc(O)c1C2=O</smiles>

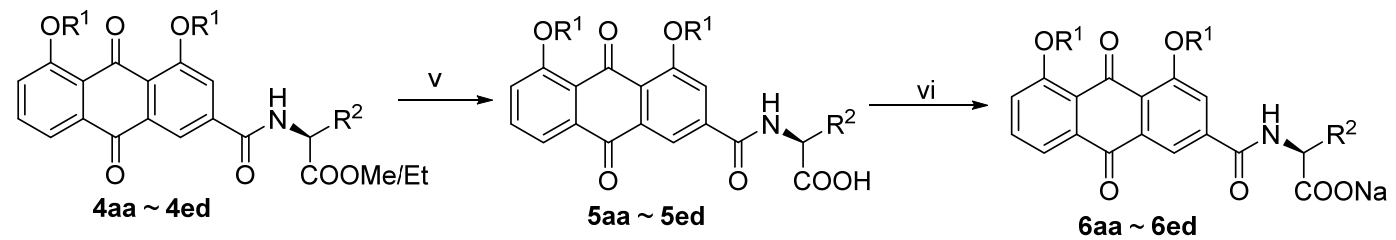

$\mathrm{R}^{1}=$ methyl, ethyl, propyl, $n$-butyl, benzyl; $\mathrm{R}^{2}=\mathrm{H}, \mathrm{CH}_{2} \mathrm{CH}\left(\mathrm{CH}_{3}\right)_{2}, \mathrm{CH}_{2} \mathrm{Ph}, \mathrm{CH}_{2} \mathrm{CH}_{2} \mathrm{SCH}_{3}$

Reagents and conditions: (i) $\mathrm{SOCl}_{2}$, EtOH, reflux; (ii) $\mathrm{R}^{1} \mathrm{X}, \mathrm{NaH}, \mathrm{DMF}, 90 \sim 130{ }^{\circ} \mathrm{C}$; (iii) $1 \mathrm{~mol} / \mathrm{L} \mathrm{NaOH}$ (aq.), r.t. $\sim 60{ }^{\circ} \mathrm{C}$; then $1 \mathrm{~mol} / \mathrm{L} \mathrm{HCl}$ (aq.), r.t.; (iv) $\mathrm{NH}_{2} \mathrm{CH}\left(\mathrm{R}^{2}\right) \mathrm{COOMe} / \mathrm{Et}$, $\mathrm{EDCl}$, DMAP, $\mathrm{CH}_{2} \mathrm{Cl}_{2}$, r.t.; (v) $1 \mathrm{~mol} / \mathrm{L} \mathrm{NaOH} \mathrm{EtOH,} \mathrm{r.t.;} \mathrm{then} 1 \mathrm{~mol} / \mathrm{L} \mathrm{HCl}$ (aq.), r.t.; (vi) $1 \mathrm{~mol} / \mathrm{L} \mathrm{NaOH}$ (aq.), $\mathrm{EtOH}$, r.t.

图式 2 目标化合物的合成路线

Scheme 2 Synthetic route of the target compounds 
表 1 化合物的体外抗肿瘤活性

Table 1 Anti-tumor activity of derivatives in vitro

\begin{tabular}{|c|c|c|c|c|c|c|c|}
\hline \multirow{2}{*}{ Compd. } & \multirow{2}{*}{$\mathrm{R}^{1}$} & \multirow{2}{*}{$\mathrm{R}^{2}$} & \multicolumn{5}{|c|}{$\mathrm{IC}_{50}{ }^{a} /\left(\mu \mathrm{mol} \cdot \mathrm{L}^{-1}\right)$} \\
\hline & & & Hela & MCF7 & HepG2 & $\mathrm{KB}$ & HEK293T \\
\hline 6aa & $\mathrm{CH}_{3}$ & $\mathrm{H}$ & $>100$ & $>100$ & $>100$ & $>100$ & $>100$ \\
\hline $6 \mathbf{a b}$ & $\mathrm{CH}_{3}$ & $\mathrm{CH}_{2} \mathrm{CH}\left(\mathrm{CH}_{3}\right)_{2}$ & $>100$ & $>100$ & $>100$ & $>100$ & $>100$ \\
\hline 6ac & $\mathrm{CH}_{3}$ & $\mathrm{CH}_{2} \mathrm{Ph}$ & $>100$ & $>100$ & $>100$ & $>100$ & $>100$ \\
\hline 6ad & $\mathrm{CH}_{3}$ & $\mathrm{CH}_{2} \mathrm{CH}_{2} \mathrm{SCH}_{3}$ & $>100$ & $>100$ & $>100$ & $>100$ & $>100$ \\
\hline $6 \mathbf{b a}$ & $\mathrm{CH}_{2} \mathrm{CH}_{3}$ & $\mathrm{H}$ & $>100$ & $>100$ & $>100$ & $>100$ & $>100$ \\
\hline $6 \mathbf{b b}$ & $\mathrm{CH}_{2} \mathrm{CH}_{3}$ & $\mathrm{CH}_{2} \mathrm{CH}\left(\mathrm{CH}_{3}\right)_{2}$ & $>100$ & $>100$ & $>100$ & $>100$ & $>100$ \\
\hline $6 \mathrm{bc}$ & $\mathrm{CH}_{2} \mathrm{CH}_{3}$ & $\mathrm{CH}_{2} \mathrm{Ph}$ & $>100$ & $>100$ & $>100$ & $>100$ & $>100$ \\
\hline 6bd & $\mathrm{CH}_{2} \mathrm{CH}_{3}$ & $\mathrm{CH}_{2} \mathrm{CH}_{2} \mathrm{SCH}_{3}$ & $>100$ & $>100$ & $>100$ & $>100$ & $>100$ \\
\hline $6 \mathrm{ca}$ & $\mathrm{CH}_{2} \mathrm{CH}_{2} \mathrm{CH}_{3}$ & $\mathrm{H}$ & $>100$ & $>100$ & $>100$ & $>100$ & $>100$ \\
\hline $6 \mathrm{cb}$ & $\mathrm{CH}_{2} \mathrm{CH}_{2} \mathrm{CH}_{3}$ & $\mathrm{CH}_{2} \mathrm{CH}\left(\mathrm{CH}_{3}\right)_{2}$ & 75.8 & 22.8 & 79.1 & 62.6 & $>100$ \\
\hline $6 \mathrm{cc}$ & $\mathrm{CH}_{2} \mathrm{CH}_{2} \mathrm{CH}_{3}$ & $\mathrm{CH}_{2} \mathrm{Ph}$ & $>100$ & 95.4 & 81.6 & 68.8 & 97.6 \\
\hline $6 \mathrm{~cd}$ & $\mathrm{CH}_{2} \mathrm{CH}_{2} \mathrm{CH}_{3}$ & $\mathrm{CH}_{2} \mathrm{CH}_{2} \mathrm{SCH}_{3}$ & $>100$ & $>100$ & $>100$ & $>100$ & $>100$ \\
\hline $6 \mathrm{da}$ & $\mathrm{CH}_{2} \mathrm{CH}_{2} \mathrm{CH}_{2} \mathrm{CH}_{3}$ & $\mathrm{H}$ & $>100$ & $>100$ & $>100$ & 64.5 & 28.4 \\
\hline $6 \mathrm{db}$ & $\mathrm{CH}_{2} \mathrm{CH}_{2} \mathrm{CH}_{2} \mathrm{CH}_{3}$ & $\mathrm{CH}_{2} \mathrm{CH}\left(\mathrm{CH}_{3}\right)_{2}$ & 62.1 & 80.2 & 51.2 & 27.7 & 37.4 \\
\hline $6 \mathrm{dc}$ & $\mathrm{CH}_{2} \mathrm{CH}_{2} \mathrm{CH}_{2} \mathrm{CH}_{3}$ & $\mathrm{CH}_{2} \mathrm{Ph}$ & 70.2 & $>100$ & 42.3 & 43.4 & 52.2 \\
\hline 6dd & $\mathrm{CH}_{2} \mathrm{CH}_{2} \mathrm{CH}_{2} \mathrm{CH}_{3}$ & $\mathrm{CH}_{2} \mathrm{CH}_{2} \mathrm{SCH}_{3}$ & $>100$ & $>100$ & $>100$ & 62.4 & 83.2 \\
\hline 6ea & $\mathrm{CH}_{2} \mathrm{Ph}$ & $\mathrm{H}$ & $>100$ & $>100$ & $>100$ & $>100$ & $>100$ \\
\hline $6 \mathrm{eb}$ & $\mathrm{CH}_{2} \mathrm{Ph}$ & $\mathrm{CH}_{2} \mathrm{CH}\left(\mathrm{CH}_{3}\right)_{2}$ & 41.9 & 44.4 & 31.7 & 26.7 & 24.1 \\
\hline $6 \mathrm{ec}$ & $\mathrm{CH}_{2} \mathrm{Ph}$ & $\mathrm{CH}_{2} \mathrm{Ph}$ & 50.1 & $>100$ & 64.6 & 64.3 & $>100$ \\
\hline 6ed & $\mathrm{CH}_{2} \mathrm{Ph}$ & $\mathrm{CH}_{2} \mathrm{CH}_{2} \mathrm{SCH}_{3}$ & $>100$ & $>100$ & $>100$ & 99.8 & $>100$ \\
\hline 顺铂 & - & - & 5.5 & 15.8 & 14.3 & 6.1 & 3.3 \\
\hline 阿霉素 & - & - & 0.99 & 2.8 & 4.7 & 3.7 & 0.7 \\
\hline
\end{tabular}

${ }^{a}$ The data represent the mean values of three independent determinations.

同程度的荧光猝灭. 这恰恰表明, 这两个化合物与 DNA 作用方式具有相似性, 即葱环进入了 DNA 双螺旋结构 的影响区域 ${ }^{[27]}$. 比较化合物 $6 \mathrm{db}$ 和 $6 \mathrm{eb}$ 的结构, 可以看 出两个化合物 C-3 位具有相同的氨基酸残基, C- 1,8 位为 分别为丁氧基和苄氧基, 具有较高的结构相似性, 因而 两个化合物与 DNA 相互作用的苂光光谱未显示明显差 别. $6 \mathbf{d b}$ 与 DNA 的相互作用方式更接近于长链类脂化合 物的表面活性作用, 推测它与 DNA 的作用可能仅是静 电结合或分子部分嵌入 DNA.

\section{2 结论}

本文以大黄酸为原料，经过酯化、烷基化、水解、 缩合等步骤, 设计合成了 20 个未见文献报道的大黄酸氨基酸缀合物, 达到了预期目标. 通过 ${ }^{1} \mathrm{H} N M R,{ }^{13} \mathrm{C}$ NMR 和 HRMS 确证了该系列化合物的结构, 采用 MTT 法研究了化合物对子宫颈癌细胞(Hela)、人肝癌细 胞(HepG-2)、人乳腺癌细胞(MCF-7)、人口腔表皮癌细 胞(KB)和人胚肾细胞(HEK293T)的体外生长抑制活性, 部分化合物对肿瘤细胞具有一定的生长抑制作用. 化合 物 $6 \mathrm{db}$ 和 $6 \mathrm{eb}$ 与 DNA 的相互作用均出现不同程度的荧 光猝灭, 表明该类化合物是 DNA 嵌入剂. 本研究对大 黄酸衍生物的研究提供了实验与理论基础, 具有一定的 指导意义.

\section{3 实验部分}

\section{1 仪器与试剂}

WRS-1B 型数字熔点仪(上海精密科学仪器有限公 司); FT/IR-360 型红外光谱仪(美国 Nicolet 公司); ZF-2 型紫外分析仪(上海安亭电子仪器厂); Bruker Avance III $\mathrm{HD} 400$ 核磁共振仪 $\left(\mathrm{CDCl}_{3}\right.$ 或 DMSO- $d_{6}$ 为溶剂, TMS 为 内标, 美国布鲁克公司); AL104 型分析天平(瑞士梅特 勒); Synergy 2 多功能酶标仪 (美国伯腾仪器有限公司 (BioTek); F-2500 型苂光光谱仪(日立高新技术公司); 全 自动旋光仪(鲁道夫 Autopol V 型); 柱色谱用硅胶(200 300 目, 青岛海洋化工有限公司); $\mathrm{IC}_{50}$ 浓度计算软件为 Origin 9.0.

大黄酸(分析纯，多点化学); 碘甲烷、溴乙烷、溴丙 烷、1-溴丁烷、澳化苄等烷基化试剂均为分析纯，购自 于阿拉丁试剂公司; 甘氨酸乙酯盐酸盐、苯丙氨酸乙酯 盐酸盐、亮氨酸甲酯盐酸盐和蛋氨酸甲酯盐酸盐均为分 析纯，购自于 Adamas 试剂公司.

\section{2 化合物的合成}

\subsection{1 中间体 2 的合成}

将大黄酸 $2.84 \mathrm{~g}(10 \mathrm{mmol})$ 、无水乙醇 $40 \mathrm{~mL}$ 和 $\mathrm{SOCl}_{2} 10 \mathrm{~mL}$ 加入到 $250 \mathrm{~mL}$ 圆底烧瓶中, 加热至回流反 应 $24 \mathrm{~h}$, 待原料完全转化完毕, 直接将反应液倒入 $1 \mathrm{~L}$ 

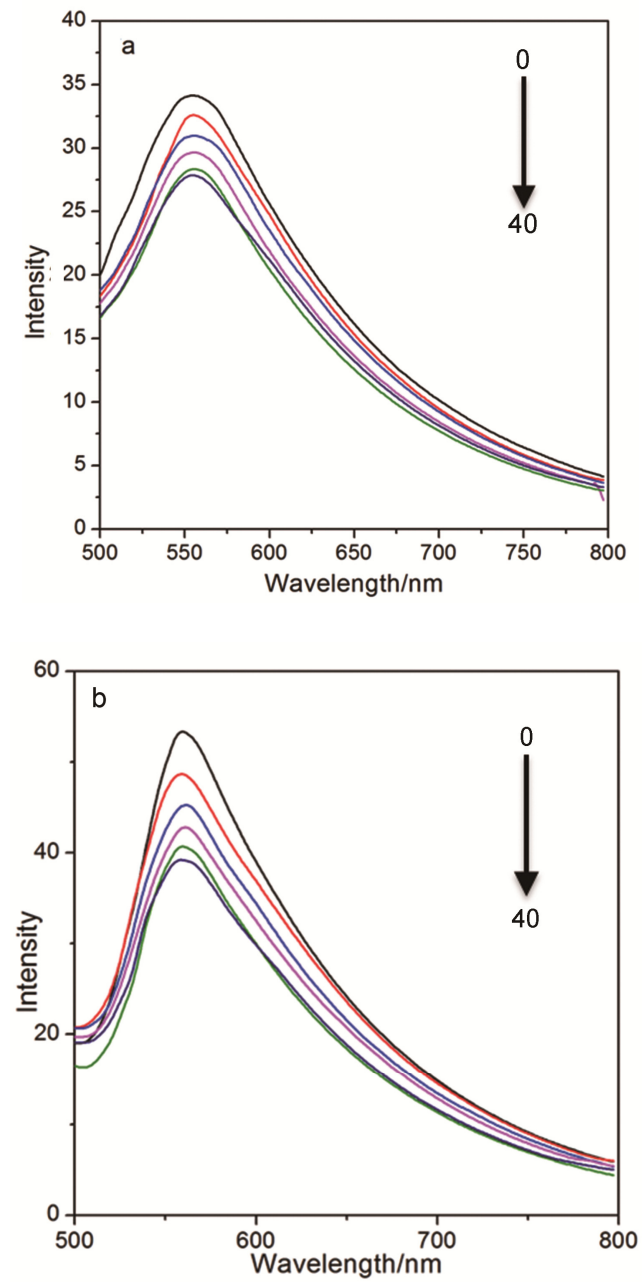

图 2 化合物 6db (a) 和 6eb (b)与 DNA 作用的荧光光谱图

Figure 2 Spectrofluorimetric tiration of $\mathbf{6 d b}$ (a) and 6eb (b) interacting with DNA

的蒸馏水中, 抽滤, 并用大量的蒸馏水洗涤固体, 固体 在真空干燥箱中充分干燥, 得到 $2.934 \mathrm{~g}$ 化合物 2 , 产率 为 $94 \%$. 直接投入下步反应.

\subsection{2中间体 $3 \mathrm{a} \sim 3 \mathrm{e}$ 的合成}

在 $100 \mathrm{~mL}$ 的圆底烧瓶中加入化合物 $2(1 \mathrm{mmol}, 312$ $\mathrm{mg}) 、$ DMF $50 \mathrm{~mL} 、 \mathrm{NaH}(5 \mathrm{mmol}, 200 \mathrm{mg})$ 和碘/溴代烷 烃 $12 \mathrm{mmol}$. 反应液加热到 $90 \sim 130{ }^{\circ} \mathrm{C}$ 下反应至原料点 消失(TLC 监测). 反应结束后, 将反应液倒入 $1 \mathrm{~mol} / \mathrm{L}$ 的 $30 \mathrm{~mL} \mathrm{HCl}$ 水溶液中, 并用二氯甲烷萃取, 收集有机相, 减压旋蒸得到的粗产物, 经柱层析分离[洗脱剂为 $V$ (石 油醚) $: V($ 乙酸乙酯 $)=5: 1$ ]得到粗产物. 将粗产物直接 加入到 $20 \mathrm{~mL} 1 \mathrm{~mol} / \mathrm{L}$ 的 $\mathrm{NaOH}$ 水溶液中, 室温至 $60{ }^{\circ} \mathrm{C}$ 搅拌, TLC 监测反应进程待水解完毕后, 用 $1 \mathrm{~mol} / \mathrm{L} \mathrm{HCl}$ 水溶液调节 $\mathrm{pH}$ 至 $5 \sim 6$, 待固体析出, 抽滤, 并用大量 的去离子水洗涤固体, 将固体充分干燥即得到黄色固体 $3 \mathbf{a} \sim 3 \mathrm{e}$, 产率 $46 \sim 86 \%$. 直接投入下步反应.

\subsection{3中间体 $\mathbf{4 a a} \sim \mathbf{4 e d}$ 的合成}

取化合物 $3(1.56 \mathrm{~g}, 5 \mathrm{mmol}) 、 4-N, N$-二甲氨基吡啶 (DMAP, $1.22 \mathrm{~g}, 10 \mathrm{mmol}$ )、1-(3-二甲氨基丙基)-3-乙基碳 二亚胺盐酸盐(EDCI, $1.44 \mathrm{~g}, 7.5 \mathrm{mmol}$ )和 $L$-氨基酸酯盐 酸盐 $(6 \mathrm{mmol})$ 混合, 加入 $100 \mathrm{~mL}$ 二氯甲烷，室温搅拌反 应，TLC 监测反应进程. 待反应结束后，将反应液缓慢 倒入 $150 \mathrm{~mL} \mathrm{HCl}(0.1 \mathrm{~mol} / \mathrm{L})$ 溶液中，并用二氯甲烷萃取 三次，合并有机相，无水硫酸钠干燥，浓缩. 经柱层析 分离 $[V$ (石油醚) $: V($ 乙酸乙酯 $)=2: 1]$ 纯化得黄色液体, 减压浓缩至干得目标产物.

2-(4,5-二甲氧基-9,10-葸醌-2-羧酰氨基)乙酸乙酯 (4aa): 黄色固体, 产率 84\%. m.p. $235.8 \sim 236.7{ }^{\circ} \mathrm{C} ;{ }^{1} \mathrm{H}$ NMR $\left(\mathrm{CDCl}_{3}, 400 \mathrm{MHz}\right) \delta: 8.10(\mathrm{~d}, J=1.6 \mathrm{~Hz}, 1 \mathrm{H}), 7.87$ (d, $J=1.6 \mathrm{~Hz}, 1 \mathrm{H}), 7.82(\mathrm{dd}, J=7.6,1.2 \mathrm{~Hz}, 1 \mathrm{H}), 7.65(\mathrm{t}$, $J=8.0 \mathrm{~Hz}, 1 \mathrm{H}), 7.31(\mathrm{dd}, J=0.8,8.4 \mathrm{~Hz}, 1 \mathrm{H}), 7.07$ (t, $J=$ $4.8 \mathrm{~Hz}, 1 \mathrm{H}), 4.25 \sim 4.30(\mathrm{~m}, 4 \mathrm{H}), 4.06(\mathrm{~s}, 3 \mathrm{H}), 4.01(\mathrm{~s}$, $3 \mathrm{H}), 1.33(\mathrm{t}, J=7.2 \mathrm{~Hz}, 3 \mathrm{H})$.

2-(4,5-二甲氧基-9,10-葸醌-2-甲酰氨基)-4-甲基戊 酸甲酯 (4ab): 黄色固体，产率 89\%. m.p. 106.3 $107.3{ }^{\circ} \mathrm{C} ;{ }^{1} \mathrm{H}$ NMR $\left(\mathrm{CDCl}_{3}, 400 \mathrm{MHz}\right) \delta: 8.09$ (d, $J=1.6$ $\mathrm{Hz}, 1 \mathrm{H}), 7.89$ (d, $J=1.6 \mathrm{~Hz}, 1 \mathrm{H}), 7.85$ (dd, $J=1.2,7.6 \mathrm{~Hz}$, $1 \mathrm{H}), 7.67(\mathrm{t}, J=8.0 \mathrm{~Hz}, 1 \mathrm{H}), 7.33(\mathrm{dd}, J=0.8,8.8 \mathrm{~Hz}$, $1 \mathrm{H}), 6.92(\mathrm{~d}, J=8.4 \mathrm{~Hz}, 1 \mathrm{H}), 4.85 \sim 4.91(\mathrm{~m}, 1 \mathrm{H}), 4.05(\mathrm{~s}$, $3 \mathrm{H}), 4.02(\mathrm{~s}, 3 \mathrm{H}), 3.80(\mathrm{~s}, 3 \mathrm{H}), 1.72 \sim 1.82(\mathrm{~m}, 3 \mathrm{H}), 1.02$ (d, $J=2.8 \mathrm{~Hz}, 3 \mathrm{H}), 1.01(\mathrm{~d}, J=3.2 \mathrm{~Hz}, 3 \mathrm{H})$.

2-(4,5-二甲氧基-9,10-葸醌-2-甲酰氨基)-3-苯基丙 酸乙酯 (4ac): 黄色固体，产率 73\%. m.p. 171.6 $172.5{ }^{\circ} \mathrm{C} ;{ }^{1} \mathrm{H}$ NMR $\left(\mathrm{CDCl}_{3}, 400 \mathrm{MHz}\right) \delta: 8.00$ (d, $J=1.6$ $\mathrm{Hz}, 1 \mathrm{H}), 7.83(\mathrm{dd}, J=1.2,8.0 \mathrm{~Hz}, 1 \mathrm{H}), 7.80(\mathrm{~d}, J=1.6 \mathrm{~Hz}$, $1 \mathrm{H}), 7.66(\mathrm{t}, J=8.0 \mathrm{~Hz}, 1 \mathrm{H}), 7.25 \sim 7.35(\mathrm{~m}, 4 \mathrm{H}), 7.18 \sim$ $7.21(\mathrm{~m}, 2 \mathrm{H}), 6.89(\mathrm{~d}, J=7.6 \mathrm{~Hz}, 1 \mathrm{H}), 5.05 \sim 5.10(\mathrm{~m}$, $1 \mathrm{H}), 4.24$ (q, $J=7.2 \mathrm{~Hz}, 2 \mathrm{H}), 4.04(\mathrm{~s}, 3 \mathrm{H}), 4.01(\mathrm{~s}, 3 \mathrm{H})$, $3.23 \sim 3.34(\mathrm{~m}, 2 \mathrm{H}), 1.29(\mathrm{t}, J=7.2 \mathrm{~Hz}, 3 \mathrm{H})$.

2-(4,5-二甲氧基-9,10-葱醌-2-甲酰氨基)-4-(甲硫基) 丁酸甲酯(4ad): 黄色固体, 产率 78\%. m.p. 68.8 $69.6{ }^{\circ} \mathrm{C} ;{ }^{1} \mathrm{H}$ NMR $\left(\mathrm{CDCl}_{3}, 400 \mathrm{MHz}\right) \delta: 8.11(\mathrm{~d}, J=1.6$ $\mathrm{Hz}, 1 \mathrm{H}), 7.86(\mathrm{~d}, J=1.6 \mathrm{~Hz}, 1 \mathrm{H}), 7.83(\mathrm{dd}, J=1.2,7.6 \mathrm{~Hz}$, 1H), 7.66 (t, $J=8.0 \mathrm{~Hz}, 1 \mathrm{H}), 7.38(\mathrm{~d}, J=7.6, \mathrm{~Hz}, 1 \mathrm{H})$, $7.32(\mathrm{dd}, J=0.8,8.4 \mathrm{~Hz}, 1 \mathrm{H}), 4.95 \sim 5.00(\mathrm{~m}, 1 \mathrm{H}), 4.05(\mathrm{~s}$, $3 \mathrm{H}), 4.01(\mathrm{~s}, 3 \mathrm{H}), 3.83(\mathrm{~s}, 3 \mathrm{H}), 2.65(\mathrm{t}, J=7.2 \mathrm{~Hz}, 2 \mathrm{H})$, $2.17 \sim 2.35(\mathrm{~m}, 2 \mathrm{H}), 2.15(\mathrm{~s}, 3 \mathrm{H})$.

2-(4,5-二乙氧基-9,10-葱醌-2-羧酰氨基)乙酸乙酯 (4ba): 黄色固体, 产率 $84 \%$. m.p. $174.8 \sim 175.3{ }^{\circ} \mathrm{C} ;{ }^{1} \mathrm{H}$ NMR $\left(\mathrm{CDCl}_{3}, 400 \mathrm{MHz}\right) \delta: 8.10(\mathrm{~d}, J=1.6 \mathrm{~Hz}, 1 \mathrm{H}), 7.86$ (d, $J=1.6 \mathrm{~Hz}, 1 \mathrm{H}), 7.82(\mathrm{dd}, J=1.2,7.6 \mathrm{~Hz}, 1 \mathrm{H}), 7.62(\mathrm{t}$, 
$J=8.0 \mathrm{~Hz}, 1 \mathrm{H}), 7.31(\mathrm{dd}, J=0.8,8.4 \mathrm{~Hz}, 1 \mathrm{H}), 7.02(\mathrm{t}, J=$ $4.8 \mathrm{~Hz}, 1 \mathrm{H}), 4.22 \sim 4.33(\mathrm{~m}, 8 \mathrm{H}), 1.55(\mathrm{t}, J=7.2 \mathrm{~Hz}, 6 \mathrm{H})$, $1.33(\mathrm{t}, J=7.2 \mathrm{~Hz}, 3 \mathrm{H})$.

2-(4,5-二乙氧基-9,10-葸醌-2-甲酰氨基)-4-甲基戊 酸甲酯 (4bb): 黄色固体, 产率 83\%. m.p. 149.6 $150.4{ }^{\circ} \mathrm{C} ;{ }^{1} \mathrm{H}$ NMR $\left(\mathrm{CDCl}_{3}, 400 \mathrm{MHz}\right) \delta: 8.07$ (d, $J=1.6$ $\mathrm{Hz}, 1 \mathrm{H}), 7.87(\mathrm{~d}, J=1.6 \mathrm{~Hz}, 1 \mathrm{H}), 7.84(\mathrm{dd}, J=0.8,7.6 \mathrm{~Hz}$, $1 \mathrm{H}), 7.63(\mathrm{t}, J=8.0 \mathrm{~Hz}, 1 \mathrm{H}), 7.32(\mathrm{dd}, J=0.8,8.4 \mathrm{~Hz}$, $1 \mathrm{H}), 6.83(\mathrm{~d}, J=8.0 \mathrm{~Hz}, 1 \mathrm{H}), 4.85 \sim 4.90(\mathrm{~m}, 1 \mathrm{H}), 4.30$ (q, $J=6.8 \mathrm{~Hz}, 2 \mathrm{H}), 4.26(\mathrm{q}, J=7.2 \mathrm{~Hz}, 2 \mathrm{H}), 3.79(\mathrm{~s}, 3 \mathrm{H})$, $1.71 \sim 1.81(\mathrm{~m}, 3 \mathrm{H}), 1.56(\mathrm{t}, J=7.2 \mathrm{~Hz}, 6 \mathrm{H}), 1.02$ (d, $J=$ $3.2 \mathrm{~Hz}, 3 \mathrm{H}), 1.00$ (d, $J=2.8 \mathrm{~Hz}, 3 \mathrm{H})$.

2-(4,5-二乙氧基-9,10-葸醌-2-甲酰氨基)-3-苯基丙 酸乙酯 (4bc): 黄色固体, 产率 92\%. m.p. 137.5 $138.1{ }^{\circ} \mathrm{C} ;{ }^{1} \mathrm{H}$ NMR $\left(\mathrm{CDCl}_{3}, 400 \mathrm{MHz}\right) \delta: 7.99$ (d, $J=1.6$ $\mathrm{Hz}, 1 \mathrm{H}), 7.83(\mathrm{dd}, J=1.2,7.6 \mathrm{~Hz}, 1 \mathrm{H}), 7.78(\mathrm{~d}, J=1.6$ $\mathrm{Hz}, 1 \mathrm{H}), 7.62(\mathrm{t}, J=8.0 \mathrm{~Hz}, 1 \mathrm{H}), 7.27 \sim 7.35(\mathrm{~m}, 4 \mathrm{H})$, $7.18 \sim 7.20(\mathrm{~m}, 2 \mathrm{H}), 6.81(\mathrm{~d}, J=7.6 \mathrm{~Hz}, 1 \mathrm{H}), 5.04 \sim 5.09$ $(\mathrm{m}, 1 \mathrm{H}), 4.21 \sim 4.31(\mathrm{~m}, 6 \mathrm{H}), 3.22 \sim 3.33(\mathrm{~m}, 2 \mathrm{H}), 1.55(\mathrm{t}$, $J=7.2 \mathrm{~Hz}, 6 \mathrm{H}), 1.28(\mathrm{t}, J=7.2 \mathrm{~Hz}, 3 \mathrm{H})$.

2-(4,5-二乙氧基-9,10-葱醌-2-甲酰氨基)-4-(甲硫基) 丁酸甲酯(4bd): 黄色固体, 产率 84\%. m.p. 168.6 $169.2{ }^{\circ} \mathrm{C} ;{ }^{1} \mathrm{H}$ NMR $\left(\mathrm{CDCl}_{3}, 400 \mathrm{MHz}\right) \delta: 8.11(\mathrm{~d}, J=1.6$ $\mathrm{Hz}, 1 \mathrm{H}), 7.86(\mathrm{~d}, J=1.6 \mathrm{~Hz}, 1 \mathrm{H}), 7.83(\mathrm{dd}, J=0.8,7.6 \mathrm{~Hz}$, $1 \mathrm{H}), 7.62(\mathrm{t}, J=8.0 \mathrm{~Hz}, 1 \mathrm{H}), 7.31(\mathrm{dd}, J=0.8,8.4 \mathrm{~Hz}$, $1 \mathrm{H}), 7.25(\mathrm{~s}, 1 \mathrm{H}), 4.94 \sim 4.99(\mathrm{~m}, 1 \mathrm{H}), 4.31$ (q, $J=7.2 \mathrm{~Hz}$, $2 \mathrm{H}), 4.25$ (q, $J=7.2 \mathrm{~Hz}, 2 \mathrm{H}), 3.82$ (s, 3H), 2.63 (t, $J=7.2$ $\mathrm{Hz}, 2 \mathrm{H}), 2.17 \sim 2.36(\mathrm{~m}, 2 \mathrm{H}), 2.15$ (s, 3H), 1.56 (t, $J=6.8$ $\mathrm{Hz}, 3 \mathrm{H}), 1.55(\mathrm{t}, J=6.8 \mathrm{~Hz}, 3 \mathrm{H})$.

2-(4,5-二丙氧基-9,10-葱醌-2-羧酰氨基)乙酸乙酯 (4ca): 黄色固体, 产率 $88 \%$. m.p. $130.8 \sim 131.7{ }^{\circ} \mathrm{C} ;{ }^{1} \mathrm{H}$ $\operatorname{NMR}\left(\mathrm{CDCl}_{3}, 400 \mathrm{MHz}\right) \delta: 8.09(\mathrm{~d}, J=1.2 \mathrm{~Hz}, 1 \mathrm{H}), 7.84$ (d, $J=1.2 \mathrm{~Hz}, 1 \mathrm{H}), 7.80(\mathrm{dd}, J=0.8,7.6 \mathrm{~Hz}, 1 \mathrm{H}), 7.61(\mathrm{t}$, $J=8.0 \mathrm{~Hz}, 1 \mathrm{H}), 7.29$ (d, $J=8.0 \mathrm{~Hz}, 1 \mathrm{H}), 7.03$ (t, $J=4.8$ $\mathrm{Hz}, 1 \mathrm{H}), 4.25 \sim 4.31(\mathrm{~m}, 4 \mathrm{H}), 4.15$ (t, $J=6.4 \mathrm{~Hz}, 2 \mathrm{H}), 4.10$ (t, $J=6.4 \mathrm{~Hz}, 2 \mathrm{H}), 1.90 \sim 1.98(\mathrm{~m}, 4 \mathrm{H}), 1.33(\mathrm{t}, J=7.2 \mathrm{~Hz}$, $3 \mathrm{H}), 1.10 \sim 1.15(\mathrm{~m}, 6 \mathrm{H})$.

2-(3,5-二丙氧基-9,10-葱醌-2-羧酰氨基)-4-甲基戊 酸甲酯 (4cb): 黄色固体, 产率 91\%. m.p. 141.5 $142.1{ }^{\circ} \mathrm{C} ;{ }^{1} \mathrm{H}$ NMR $\left(\mathrm{CDCl}_{3}, 400 \mathrm{MHz}\right) \delta$ : $8.06(\mathrm{~s}, 1 \mathrm{H})$, $7.86(\mathrm{~s}, 1 \mathrm{H}), 7.82(\mathrm{~d}, J=7.2 \mathrm{~Hz}, 1 \mathrm{H}), 7.62(\mathrm{t}, J=8.0 \mathrm{~Hz}$, $1 \mathrm{H}), 7.30(\mathrm{~d}, J=8.0 \mathrm{~Hz}, 1 \mathrm{H}), 6.80(\mathrm{~d}, J=8.0 \mathrm{~Hz}, 1 \mathrm{H})$, $4.85 \sim 4.90(\mathrm{~m}, 1 \mathrm{H}), 4.16(\mathrm{t}, J=6.4 \mathrm{~Hz}, 2 \mathrm{H}), 4.11(\mathrm{t}, J=$ $6.4 \mathrm{~Hz}, 2 \mathrm{H}), 3.79$ (s, 3H), $1.90 \sim 1.99(\mathrm{~m}, 4 \mathrm{H}), 1.71 \sim 1.81$ (m, 3H), 1.13 (q, $J=7.2 \mathrm{~Hz}, 6 \mathrm{H}), 1.02(\mathrm{~d}, J=3.2 \mathrm{~Hz}, 3 \mathrm{H})$, $1.00(\mathrm{~d}, J=2.8 \mathrm{~Hz}, 3 \mathrm{H})$.

2-(3,5-二丙氧基-9,10-葱醌-2-羧酰氨基)-3-苯基丙 酸乙酯 (4cc): 黄色固体, 产率 89\%. m.p. 138.2 $139.2{ }^{\circ} \mathrm{C} ;{ }^{1} \mathrm{H}$ NMR $\left(\mathrm{CDCl}_{3}, 400 \mathrm{MHz}\right) \delta: 7.97(\mathrm{~d}, J=1.6$ $\mathrm{Hz}, 1 \mathrm{H}), 7.81(\mathrm{dd}, J=0.8,7.6 \mathrm{~Hz}, 1 \mathrm{H}), 7.77(\mathrm{~d}, J=1.6 \mathrm{~Hz}$, $1 \mathrm{H}), 7.61(\mathrm{t}, J=8.0 \mathrm{~Hz}, 1 \mathrm{H}), 7.27 \sim 7.35(\mathrm{~m}, 4 \mathrm{H}), 7.17 \sim$ $7.20(\mathrm{~m}, 2 \mathrm{H}), 6.79(\mathrm{~d}, J=7.6 \mathrm{~Hz}, 1 \mathrm{H}), 5.04 \sim 5.09(\mathrm{~m}$, $1 \mathrm{H}), 4.24$ (q, $J=7.2 \mathrm{~Hz}, 2 \mathrm{H}), 4.14(\mathrm{t}, J=6.4 \mathrm{~Hz}, 2 \mathrm{H}), 4.10$ (t, $J=1.6 \mathrm{~Hz}, 2 \mathrm{H}), 3.22 \sim 3.33(\mathrm{~m}, 2 \mathrm{H}), 1.90 \sim 1.99(\mathrm{~m}$, $4 \mathrm{H}), 1.28(\mathrm{t}, J=7.2 \mathrm{~Hz}, 3 \mathrm{H}), 1.10 \sim 1.15(\mathrm{~m}, 6 \mathrm{H})$.

2-(3,5-二丙氧基-9,10-葱醌-2-羧酰氨基)-4-(甲硫基) 丁酸甲酯 (4cd): 黄色固体, 产率 77\%. m.p. 143.6 $144.5{ }^{\circ} \mathrm{C} ;{ }^{1} \mathrm{H}$ NMR $\left(\mathrm{CDCl}_{3}, 400 \mathrm{MHz}\right) \delta: 8.09$ (d, $J=1.6$ $\mathrm{Hz}, 1 \mathrm{H}), 7.85(\mathrm{~d}, J=1.6 \mathrm{~Hz}, 1 \mathrm{H}), 7.82(\mathrm{dd}, J=0.8,7.6 \mathrm{~Hz}$, $1 \mathrm{H}), 7.62(\mathrm{t}, J=8.0 \mathrm{~Hz}, 1 \mathrm{H}), 7.30(\mathrm{dd}, J=0.8,8.4 \mathrm{~Hz}$, $1 \mathrm{H}), 7.25(\mathrm{~d}, J=7.6 \mathrm{~Hz}, 1 \mathrm{H}), 4.94 \sim 4.99(\mathrm{~m}, 1 \mathrm{H}), 4.16(\mathrm{t}$, $J=6.4 \mathrm{~Hz}, 2 \mathrm{H}), 4.11(\mathrm{t}, J=6.4 \mathrm{~Hz}, 2 \mathrm{H}), 3.82(\mathrm{~s}, 3 \mathrm{H}), 2.63$ (t, $J=7.2 \mathrm{~Hz}, 2 \mathrm{H}), 2.17 \sim 2.35(\mathrm{~m}, 2 \mathrm{H}), 2.15(\mathrm{~s}, 3 \mathrm{H})$, $1.90 \sim 1.99(\mathrm{~m}, 4 \mathrm{H}), 1.10 \sim 1.15(\mathrm{~m}, 6 \mathrm{H})$.

2-(4,5-二丁氧基-9,10-葱醌-2-羧酰氨基) 乙酸乙酯 (4da): 黄色固体, 产率 87\%. m.p. 139.1 140.0 ${ }^{\circ} \mathrm{C} ;{ }^{1} \mathrm{H}$ NMR $\left(\mathrm{CDCl}_{3}, 400 \mathrm{MHz}\right) \delta: 8.09(\mathrm{~d}, J=1.6 \mathrm{~Hz}, 1 \mathrm{H}), 7.84$ (d, $J=1.6 \mathrm{~Hz}, 1 \mathrm{H}), 7.78(\mathrm{dd}, J=1.2,7.6 \mathrm{~Hz}, 1 \mathrm{H}), 7.59(\mathrm{t}$, $J=8.0 \mathrm{~Hz}, 1 \mathrm{H}), 7.28(\mathrm{dd}, J=1.2,8.0 \mathrm{~Hz}, 1 \mathrm{H}), 7.15(\mathrm{t}, J=$ $5.2 \mathrm{~Hz}, 1 \mathrm{H}), 4.24 \sim 4.30(\mathrm{~m}, 4 \mathrm{H}), 4.18(\mathrm{t}, J=6.4 \mathrm{~Hz}, 2 \mathrm{H})$, $4.13(\mathrm{t}, J=6.4 \mathrm{~Hz}, 2 \mathrm{H}), 1.86 \sim 1.93(\mathrm{~m}, 4 \mathrm{H}), 1.57 \sim 1.63$ (m, 4H), $1.32(\mathrm{t}, J=7.2 \mathrm{~Hz}, 3 \mathrm{H}), 0.99 \sim 1.03(\mathrm{~m}, 6 \mathrm{H})$.

2-(4,5-二丁氧基-9,10-葸醌-2-甲酰氨基)-4-甲基戊 酸甲酯(4db): 黄色固体, 产率 82\%. m.p. 73.1 73.9 ${ }^{\circ} \mathrm{C}$; ${ }^{1} \mathrm{H} \mathrm{NMR}\left(\mathrm{CDCl}_{3}, 400 \mathrm{MHz}\right) \delta: 8.05(\mathrm{~d}, J=1.6 \mathrm{~Hz}, 1 \mathrm{H})$, $7.86(\mathrm{~d}, J=1.6 \mathrm{~Hz}, 1 \mathrm{H}), 7.82(\mathrm{dd}, J=0.8,7.6 \mathrm{~Hz}, 1 \mathrm{H})$, $7.62(\mathrm{t}, J=8.0 \mathrm{~Hz}, 1 \mathrm{H}), 7.29(\mathrm{~d}, J=8.4 \mathrm{~Hz}, 1 \mathrm{H}), 6.77$ (d, $J=8.4 \mathrm{~Hz}, 1 \mathrm{H}), 4.85 \sim 4.90(\mathrm{~m}, 1 \mathrm{H}), 4.20$ (t, $J=6.4 \mathrm{~Hz}$, $2 \mathrm{H}), 4.15$ (t, $J=6.4 \mathrm{~Hz}, 2 \mathrm{H}), 3.79(\mathrm{~s}, 3 \mathrm{H}), 1.87 \sim 1.94(\mathrm{~m}$, $4 \mathrm{H}), 1.70 \sim 1.81(\mathrm{~m}, 3 \mathrm{H}), 1.55 \sim 1.66(\mathrm{~m}, 4 \mathrm{H}), 0.99 \sim 1.04$ (m, 12H).

2-(4,5-二丁氧基-9,10-葸醌-2-甲酰氨基)-3-苯基丙 酸乙酯 (4dc): 黄色固体, 产率 86\%. m.p. 135.4 $136.3{ }^{\circ} \mathrm{C} ;{ }^{1} \mathrm{H}$ NMR $\left(\mathrm{CDCl}_{3}, 400 \mathrm{MHz}\right) \delta: 7.97$ (d, $J=1.6$ $\mathrm{Hz}, 1 \mathrm{H}), 7.81(\mathrm{dd}, J=1.2,7.6 \mathrm{~Hz}, 1 \mathrm{H}), 7.77$ (d, $J=1.6 \mathrm{~Hz}$, 1H), $7.61(\mathrm{t}, J=8.0 \mathrm{~Hz}, 1 \mathrm{H}), 7.27 \sim 7.35(\mathrm{~m}, 4 \mathrm{H}), 7.17 \sim$ $7.20(\mathrm{~m}, 2 \mathrm{H}), 6.79$ (d, $J=7.6 \mathrm{~Hz}, 1 \mathrm{H}), 5.07$ (q, $J=6.0 \mathrm{~Hz}$, $1 \mathrm{H}), 4.23$ (q, $J=7.2 \mathrm{~Hz}, 2 \mathrm{H}), 4.18(\mathrm{t}, J=6.4 \mathrm{~Hz}, 2 \mathrm{H}), 4.14$ (t, $J=6.4 \mathrm{~Hz}, 2 \mathrm{H}), 3.22 \sim 3.33(\mathrm{~m}, 2 \mathrm{H}), 1.86 \sim 1.94(\mathrm{~m}$, $4 \mathrm{H}), 1.57 \sim 1.64(\mathrm{~m}, 4 \mathrm{H}), 1.28(\mathrm{t}, J=7.2 \mathrm{~Hz}, 3 \mathrm{H}), 0.99 \sim$ 
$1.03(\mathrm{~m}, 6 \mathrm{H})$.

2-(4,5-二丁氧基-9,10-蒽醌-2-甲酰氨基)-4-(甲硫基) 丁酸甲酯(4dd): 黄色固体，产率 75\%. m.p. 123.6 $124.5{ }^{\circ} \mathrm{C} ;{ }^{1} \mathrm{H}$ NMR $\left(\mathrm{CDCl}_{3}, 400 \mathrm{MHz}\right) \delta$ : 8.09 (d, $J=1.2$ $\mathrm{Hz}, 1 \mathrm{H}), 7.85$ (d, $J=1.2 \mathrm{~Hz}, 1 \mathrm{H}), 7.82$ (d, $J=7.2 \mathrm{~Hz}, 1 \mathrm{H})$, 7.62 (t, $J=8.0 \mathrm{~Hz}, 1 \mathrm{H}), 7.30$ (d, $J=8.0 \mathrm{~Hz}, 1 \mathrm{H}), 7.23$ (d, $J=7.6 \mathrm{~Hz}, 1 \mathrm{H}), 4.94 \sim 4.99(\mathrm{~m}, 1 \mathrm{H}), 4.20(\mathrm{t}, J=6.4 \mathrm{~Hz}$, $2 \mathrm{H}), 4.15(\mathrm{t}, J=6.4 \mathrm{~Hz}, 2 \mathrm{H}), 3.82(\mathrm{~s}, 3 \mathrm{H}), 2.63(\mathrm{t}, J=7.2$ $\mathrm{Hz}, 2 \mathrm{H}), 2.17 \sim 2.34(\mathrm{~m}, 2 \mathrm{H}), 2.15(\mathrm{~s}, 3 \mathrm{H}), 1.87 \sim 1.94(\mathrm{~m}$, $3 \mathrm{H}), 1.58 \sim 1.64(\mathrm{~m}, 4 \mathrm{H}), 0.99 \sim 1.04(\mathrm{~m}, 6 \mathrm{H})$.

2-[4,5-双(芰氧基)- 9,10 -蒽醌-2-羧酰氨基]乙酸乙酯 (4ea): 黄色固体, 产率 $88 \%$. m.p. $144.6 \sim 145.3{ }^{\circ} \mathrm{C} ;{ }^{1} \mathrm{H}$ $\mathrm{NMR}\left(\mathrm{CDCl}_{3}, 400 \mathrm{MHz}\right) \delta: 8.11(\mathrm{~d}, J=1.6 \mathrm{~Hz}, 1 \mathrm{H}), 7.92$ $(\mathrm{d}, J=1.6 \mathrm{~Hz}, 1 \mathrm{H}), 7.83(\mathrm{dd}, J=1.2,7.6 \mathrm{~Hz}, 1 \mathrm{H}), 7.57 \sim$ $7.65(\mathrm{~m}, 5 \mathrm{H}), 7.37 \sim 7.41(\mathrm{~m}, 4 \mathrm{H}), 7.32 \sim 7.35(\mathrm{~m}, 3 \mathrm{H})$, $7.04(\mathrm{t}, J=5.2 \mathrm{~Hz}, 1 \mathrm{H}), 5.33(\mathrm{~s}, 2 \mathrm{H}), 5.29(\mathrm{~s}, 2 \mathrm{H}), 4.24 \sim$ $4.30(\mathrm{~m}, 4 \mathrm{H}), 1.33(\mathrm{t}, J=7.2 \mathrm{~Hz}, 3 \mathrm{H})$.

2-[4,5-双(苄氧基)-9,10-葱醌-2-甲酰氨基]-4-甲基戊 酸甲酯(4eb): 黄色固体, 产率 $82 \%$. m.p. 85.7 $86.5{ }^{\circ} \mathrm{C}$; ${ }^{1} \mathrm{H} \mathrm{NMR}\left(\mathrm{CDCl}_{3}, 400 \mathrm{MHz}\right) \delta: 8.11(\mathrm{~d}, J=1.6 \mathrm{~Hz}, 1 \mathrm{H})$, $7.94(\mathrm{~d}, J=1.6 \mathrm{~Hz}, 1 \mathrm{H}), 7.87(\mathrm{dd}, J=1.2,7.6 \mathrm{~Hz}, 1 \mathrm{H})$, $7.60 \sim 7.66(\mathrm{~m}, 5 \mathrm{H}), 7.33 \sim 7.42(\mathrm{~m}, 7 \mathrm{H}), 6.82(\mathrm{~d}, J=8.4$ $\mathrm{Hz}, 1 \mathrm{H}), 5.35(\mathrm{~s}, 2 \mathrm{H}), 5.31(\mathrm{~s}, 2 \mathrm{H}), 4.85 \sim 4.90(\mathrm{~m}, 1 \mathrm{H})$, $3.80(\mathrm{~s}, 3 \mathrm{H}), 1.71 \sim 1.81(\mathrm{~m}, 3 \mathrm{H}), 1.02(\mathrm{~d}, J=2.0 \mathrm{~Hz}, 3 \mathrm{H})$, $1.00(\mathrm{~d}, J=2.0 \mathrm{~Hz}, 3 \mathrm{H})$.

2-[4,5-双(苄氧基)-9,10-蒽醌-2-甲酰氨基]-3-苯基丙 酸乙酯(4ec): 黄色固体, 产率 90\%. m.p. 92.5 93.3 ${ }^{\circ} \mathrm{C}$; ${ }^{1} \mathrm{H} \mathrm{NMR}\left(\mathrm{CDCl}_{3}, 400 \mathrm{MHz}\right) \delta: 8.03(\mathrm{~d}, J=1.6 \mathrm{~Hz}, 1 \mathrm{H})$, $7.87(\mathrm{dd}, J=1.2,8.0 \mathrm{~Hz}, 2 \mathrm{H}), 7.60 \sim 7.66(\mathrm{~m}, 5 \mathrm{H}), 7.28 \sim$ $7.42(\mathrm{~m}, 10 \mathrm{H}), 7.17 \sim 7.19(\mathrm{~m}, 1 \mathrm{H}), 6.77(\mathrm{~d}, J=8.0 \mathrm{~Hz}$, $1 \mathrm{H}), 5.36(\mathrm{~s}, 2 \mathrm{H}), 5.32(\mathrm{~s}, 2 \mathrm{H}), 5.04 \sim 5.09(\mathrm{~m}, 1 \mathrm{H}), 4.24$ $(\mathrm{q}, J=7.2 \mathrm{~Hz}, 2 \mathrm{H}), 3.23 \sim 3.34(\mathrm{~m}, 2 \mathrm{H}), 1.29(\mathrm{t}, J=7.2$ $\mathrm{Hz}, 3 \mathrm{H})$.

2-[4,5-双(苠氧基)-9,10-蒽醌-2-甲酰氨基]-4-(甲硫 基)丁酸甲酯(4ed): 黄色固体, 产率 63\%. m.p. 125.4 $126.2{ }^{\circ} \mathrm{C} ;{ }^{1} \mathrm{H}$ NMR $\left(\mathrm{CDCl}_{3}, 400 \mathrm{MHz}\right) \delta$ : 8.14 (d, $J=1.6$ $\mathrm{Hz}, 1 \mathrm{H}), 7.95(\mathrm{~d}, J=1.6 \mathrm{~Hz}, 1 \mathrm{H}), 7.87(\mathrm{dd}, J=0.8,7.6 \mathrm{~Hz}$, $1 \mathrm{H}), 7.61 \sim 7.67(\mathrm{~m}, 5 \mathrm{H}), 7.33 \sim 7.42(\mathrm{~m}, 7 \mathrm{H}), 7.23(\mathrm{~d}, J=$ $7.6 \mathrm{~Hz}, 1 \mathrm{H}), 5.37(\mathrm{~s}, 2 \mathrm{H}), 5.32(\mathrm{~s}, 2 \mathrm{H}), 4.94 \sim 4.99(\mathrm{~m}$, $1 \mathrm{H}), 3.83(\mathrm{~s}, 3 \mathrm{H}), 2.63(\mathrm{t}, J=7.6 \mathrm{~Hz}, 2 \mathrm{H}), 2.28 \sim 2.36(\mathrm{~m}$, $1 \mathrm{H}), 2.16 \sim 2.22(\mathrm{~m}, 1 \mathrm{H}), 2.15(\mathrm{~s}, 3 \mathrm{H})$.

\section{2 .4 化合物 5aa 5ed 的合成}

取化合物 4 (1 mmol) 溶于 $10 \mathrm{~mL}$ 乙醇中, 滴加 20 $\mathrm{mL} \mathrm{NaOH}(1 \mathrm{mmol} / \mathrm{L})$ 溶液, 室温至 $70^{\circ} \mathrm{C}$ 搅拌反应, TLC 监测反应进程. 待反应结束, 将反应液缓慢倒入 20
$\mathrm{mL} \mathrm{HCl}(1 \mathrm{mmol} / \mathrm{L})$ 溶液中, 搅拌的过程中会析出黄色 固体, 直接将固体过滤, 并用大量的蒸馏水洗涤固体, 即得化合物 5aa $\sim 5$ ed.

2-(4,5-二甲氧基-9,10-蒽醌-2-羧酰氨基)乙酸(5aa): 黄色固体, 产率 78\%. m.p. 203.5 204.5 ${ }^{\circ} \mathrm{C} ;{ }^{1} \mathrm{H}$ NMR (DMSO- $\left.d_{6}, 400 \mathrm{MHz}\right) \delta: 9.28(\mathrm{t}, J=6.0 \mathrm{~Hz}, 1 \mathrm{H}), 8.19$ (d, $J=1.6 \mathrm{~Hz}, 1 \mathrm{H}), 7.91(\mathrm{~d}, J=1.6 \mathrm{~Hz}, 1 \mathrm{H}), 7.78(\mathrm{t}, J=8.0$ $\mathrm{Hz}, 1 \mathrm{H}), 7.72$ (dd, $J=1.2,8.0 \mathrm{~Hz}, 1 \mathrm{H}), 7.56$ (dd, $J=1.2$, $8.4 \mathrm{~Hz}, 1 \mathrm{H}), 3.99$ (s, 3H), 3.98(s, 2H), 3.93 (s, 3H); ${ }^{13} \mathrm{C}$ NMR (DMSO- $\left.d_{6}, 100 \mathrm{MHz}\right) \delta: 182.7,180.8,172.2,163.5$, $158.7,158.7,139.6,134.2,133.9,133.8,124.5,123.4$, $119.0,118.1,116.8,116.7,56.5,56.3,44.4$. HRMS calcd for $\mathrm{C}_{19} \mathrm{H}_{14} \mathrm{NO}_{7}[\mathrm{M}-\mathrm{H}]^{-}$368.0776, found 368.0778.

2-(4,5-二甲氧基-9,10-葱醌-2-甲酰氨基)-4-甲基戊 酸(5ab): 黄色固体, 产率 79\%. m.p. $127.5 \sim 128.5{ }^{\circ} \mathrm{C}$; $[\alpha]_{\mathrm{D}}^{25}-5.1$ (c $\left.0.1, \mathrm{MeOH}\right) ;{ }^{1} \mathrm{H}$ NMR (DMSO- $d_{6}, 400$ MHz) $\delta: 12.72$ (s, 1H), 9.08 (d, $J=8.0 \mathrm{~Hz}, 1 \mathrm{H}), 8.23$ (s, 1H), 7.90 (s, 1H), 7.78 (t, $J=7.6 \mathrm{~Hz}, 1 \mathrm{H}), 7.72$ (d, $J=7.2$ $\mathrm{Hz}, 1 \mathrm{H}), 7.56(\mathrm{~d}, J=8.0 \mathrm{~Hz}, 1 \mathrm{H}), 4.49 \sim 4.55(\mathrm{~m}, 1 \mathrm{H})$, $4.00(\mathrm{~s}, 3 \mathrm{H}), 3.93(\mathrm{~s}, 3 \mathrm{H}), 1.79 \sim 1.85(\mathrm{~m}, 1 \mathrm{H}), 1.65 \sim 1.76$ (m, 2H), 0.95 (d, $J=6.0 \mathrm{~Hz}, 3 \mathrm{H}), 0.91(\mathrm{~d}, J=6.0 \mathrm{~Hz}, 3 \mathrm{H})$; ${ }^{13} \mathrm{C}$ NMR (DMSO- $\left.d_{6}, 100 \mathrm{MHz}\right) \delta$ : 182.9, 180.9, 173.9, $164.7,158.8,138.6,134.4,134.2,134.1,125.3,123.4$, 119.0, 118.2, 117.1, 117.0, 109.6, 56.5, 56.4, 51.1, 24.5, 22.9, 21.2. HRMS calcd for $\mathrm{C}_{23} \mathrm{H}_{22} \mathrm{NO}_{7}[\mathrm{M}-\mathrm{H}]$ 424.1402 , found 424.1404 .

2-(4,5-二甲氧基-9,10-蒽醌-2-羧酰氨基)-3-苯基丙 酸(5ac): 黄色固体, 产率 70\%. m.p. 130.2 130.8 ${ }^{\circ} \mathrm{C}$; $[\alpha]_{\mathrm{D}}^{25}-80.4$ (c $\left.0.1, \mathrm{MeOH}\right) ;{ }^{1} \mathrm{H}$ NMR (DMSO- $d_{6}, 400$ MHz) $\delta: 12.85$ (s, 1H), 9.19 (d, $J=8.4 \mathrm{~Hz}, 1 \mathrm{H}), 8.14$ (s, $1 \mathrm{H}), 7.70 \sim 7.78(\mathrm{~m}, 3 \mathrm{H}), 7.54(\mathrm{~d}, J=8.4 \mathrm{~Hz}, 1 \mathrm{H}), 7.34$ (d, $J=7.2 \mathrm{~Hz}, 2 \mathrm{H}), 7.29$ (t, $J=7.2 \mathrm{~Hz} 2 \mathrm{H}), 7.19$ (t, $J=7.2 \mathrm{~Hz}$, $1 \mathrm{H}), 4.67 \sim 4.73(\mathrm{~m}, 1 \mathrm{H}), 3.97(\mathrm{~s}, 3 \mathrm{H}), 3.92(\mathrm{~s}, 3 \mathrm{H}), 3.25$ $(\mathrm{dd}, J=4.4,13.6 \mathrm{~Hz}, 1 \mathrm{H}), 3.12(\mathrm{t}, J=10.8 \mathrm{~Hz}, 1 \mathrm{H}) ;{ }^{13} \mathrm{C}$ NMR (DMSO- $\left.d_{6}, 100 \mathrm{MHz}\right) \delta: 182.9,180.9,172.9,164.7$, $158.7,158.7,138.5,138.0,134.4,134.2,134.1,129.1$, $128.2,126.4,125.2,123.4,119.0,118.2,117.0,116.9$, 56.5, 56.3, 54.3, 36.3. HRMS calcd for $\mathrm{C}_{26} \mathrm{H}_{20} \mathrm{NO}_{7}[\mathrm{M}-$ $\mathrm{H}]^{-} \quad 458.1245$, found 458.1249 .

2-(4,5-二甲氧基-9,10-蒽醌-2-甲酰氨基)-4-(甲硫基) 丁酸(5ad): 黄色固体, 产率 $80 \%$. m.p. 140.6 141.2 ${ }^{\circ} \mathrm{C}$; $[\alpha]_{\mathrm{D}}^{25}-20.6$ (c $\left.0.1, \mathrm{MeOH}\right) ;{ }^{1} \mathrm{H}$ NMR (DMSO- $d_{6}, 400$ MHz) $\delta: 8.90(\mathrm{~d}, J=7.6 \mathrm{~Hz}, 1 \mathrm{H}), 8.18(\mathrm{~d}, J=1.2 \mathrm{~Hz}, 1 \mathrm{H})$, 7.89 (d, $J=1.2 \mathrm{~Hz}, 1 \mathrm{H}), 7.77$ (t, $J=8.0 \mathrm{~Hz}, 1 \mathrm{H}), 7.71$ (dd, $J=1.2,7.6 \mathrm{~Hz}, 1 \mathrm{H}), 7.55(\mathrm{dd}, J=1.2,8.0 \mathrm{~Hz}, 1 \mathrm{H}), 4.49 \sim$ 
$4.54(\mathrm{~m}, 1 \mathrm{H}), 3.99(\mathrm{~s}, 3 \mathrm{H}), 3.93(\mathrm{~s}, 3 \mathrm{H}), 2.54 \sim 2.60(\mathrm{~m}$, $2 \mathrm{H}), 2.07 \sim 2.14(\mathrm{~m}, 2 \mathrm{H}), 2.06(\mathrm{~s}, 3 \mathrm{H}) ;{ }^{13} \mathrm{C} \quad \mathrm{NMR}$ (DMSO- $\left.d_{6}, 100 \mathrm{MHz}\right) \delta: 183.0,181.0,164.7,158.8,138.8$, $134.5,134.2,134.1,125.2,123.4,119.0,118.2,117.1$, 117.0, 56.6, 56.4, 56.1, 52.5, 30.6, 30.2, 18.6, 14.6. HRMS calcd for $\mathrm{C}_{22} \mathrm{H}_{20} \mathrm{NO}_{7} \mathrm{~S}[\mathrm{M}-\mathrm{H}]^{-}$442.0966, found 442.0969 .

2-(4,5-二乙氧基-9,10-葱醌-2-羊酰氨基) 乙酸 $(\mathbf{5 b a})$ : 黄色固体, 产率 $85 \%$. m.p. $230.9 \sim 231.7{ }^{\circ} \mathrm{C} ;{ }^{1} \mathrm{H}$ NMR (DMSO- $\left.d_{6}, 400 \mathrm{MHz}\right) \delta: 12.70(\mathrm{~s}, 1 \mathrm{H}), 9.27(\mathrm{t}, J=5.6 \mathrm{~Hz}$, $1 \mathrm{H}), 8.18(\mathrm{~d}, J=1.6 \mathrm{~Hz}, 1 \mathrm{H}), 7.89$ (d, $J=1.6 \mathrm{~Hz}, 1 \mathrm{H}), 7.74$ $(\mathrm{t}, J=7.6 \mathrm{~Hz}, 1 \mathrm{H}), 7.71(\mathrm{dd}, J=1.6,7.6 \mathrm{~Hz}, 1 \mathrm{H}), 7.54(\mathrm{dd}$, $J=1.6,7.6 \mathrm{~Hz}, 1 \mathrm{H}), 4.28$ (q, $J=7.2 \mathrm{~Hz}, 2 \mathrm{H}), 4.22$ (q, $J=$ $7.2 \mathrm{~Hz}, 2 \mathrm{H}), 3.98$ (d, $J=6.0 \mathrm{~Hz}, 2 \mathrm{H}), 1.44$ (t, $J=7.2 \mathrm{~Hz}$, $3 \mathrm{H}$ ), $1.41\left(\mathrm{t}, J=7.2 \mathrm{~Hz}, 3 \mathrm{H}\right.$ ); ${ }^{13} \mathrm{C}$ NMR (DMSO- $d_{6}, 100$ MHz) $\delta: 183.0,180.6,171.0,164.8,158.2,158.1,138.2$, $134.3,134.1,125.3,123.5,120.1,118.2,117.9,116.8$, 65.0, 64.7, 41.4, 14.6. HRMS calcd for $\mathrm{C}_{21} \mathrm{H}_{18} \mathrm{NO}_{7}[\mathrm{M}-$ $\mathrm{H}]^{-}$396.1089, found 396.1085 .

2-(4,5-二乙氧基-9,10-葱醌-2-甲酰氨基)-4-甲基戊 酸(5bb): 黄色固体, 产率 $87 \%$. m.p. $108.5 \sim 109.5{ }^{\circ} \mathrm{C}$; $[\alpha]_{\mathrm{D}}^{25}-0.9$ (c $\left.0.1, \mathrm{MeOH}\right) ;{ }^{1} \mathrm{H}$ NMR (DMSO- $d_{6}, 400$ MHz) $\delta: 12.68(\mathrm{~s}, 1 \mathrm{H}), 9.07(\mathrm{~d}, J=7.2 \mathrm{~Hz}, 1 \mathrm{H}), 8.23(\mathrm{~s}$, $1 \mathrm{H}), 7.89(\mathrm{~s}, 1 \mathrm{H}), 7.70 \sim 7.76(\mathrm{~m}, 2 \mathrm{H}), 7.54(\mathrm{~d}, J=7.6 \mathrm{~Hz}$, $1 \mathrm{H}), 4.51(\mathrm{t}, J=10.8 \mathrm{~Hz}, 1 \mathrm{H}), 4.29$ (q, $J=7.2 \mathrm{~Hz}, 2 \mathrm{H})$, $4.22(\mathrm{q}, J=7.2 \mathrm{~Hz}, 2 \mathrm{H}), 1.81(\mathrm{t}, J=10.8 \mathrm{~Hz}, 1 \mathrm{H}), 1.64 \sim$ $1.72(\mathrm{~m}, 2 \mathrm{H}), 1.42$ (q, $J=6.4 \mathrm{~Hz}, 6 \mathrm{H}), 0.95(\mathrm{~d}, J=5.6 \mathrm{~Hz}$, $3 \mathrm{H}), 0.90(\mathrm{~d}, J=5.6 \mathrm{~Hz}, 3 \mathrm{H}) ;{ }^{13} \mathrm{C}$ NMR (DMSO- $d_{6}, 100$ MHz) $\delta: 183.0,180.6,173.9,164.8,158.2,158.1,138.4$, $134.3,134.3,134.2,125.3,123.5,120.1,118.2,117.1$, 65.0, 64.7, 51.1, 24.5, 22.9, 21.2, 14.6. HRMS calcd for $\mathrm{C}_{25} \mathrm{H}_{26} \mathrm{NO}_{7}[\mathrm{M}-\mathrm{H}]^{-}$452.1715, found 452.1709.

2-(4,5-二乙氧基-9,10-葸醌-2-羧酰氨基)-3-苯基丙 酸(5bc): 黄色固体, 产率 74\%. m.p. 213.6 214.0 ${ }^{\circ} \mathrm{C}$; $[\alpha]_{\mathrm{D}}^{25}-78.8$ ( $c$ 0.1, MeOH); ${ }^{1} \mathrm{H}$ NMR (DMSO- $d_{6}, 400$ MHz) $\delta: 9.16(\mathrm{~d}, J=8.0 \mathrm{~Hz}, 1 \mathrm{H}), 8.13(\mathrm{~s}, 1 \mathrm{H}), 7.70-7.76$ (m, 3H), 7.54 (d, $J=8.0 \mathrm{~Hz}, 1 \mathrm{H}), 7.34$ (d, $J=7.2 \mathrm{~Hz}, 2 \mathrm{H})$, $7.28(\mathrm{t}, J=7.6 \mathrm{~Hz}, 2 \mathrm{H}), 7.19(\mathrm{t}, J=7.2 \mathrm{~Hz}, 1 \mathrm{H}), 4.65 \sim$ $4.71(\mathrm{~m}, 1 \mathrm{H}), 4.27(\mathrm{q}, J=6.8 \mathrm{~Hz}, 2 \mathrm{H}), 4.22(\mathrm{q}, J=6.8 \mathrm{~Hz}$, $2 \mathrm{H}), 3.25$ (dd, $J=4.8,13.6 \mathrm{~Hz}, 1 \mathrm{H}), 3.10$ (q, $J=10.8 \mathrm{~Hz}$, 1H), 1.42 (q, $J=7.2 \mathrm{~Hz}, 6 \mathrm{H}$ ); ${ }^{13} \mathrm{C}$ NMR (DMSO- $d_{6}, 100$ MHz) $\delta: 183.0,180.6,172.9,164.6,158.1,158.0,138.4$, $138.1,134.3,134.3,134.1,129.1,128.2,126.4,125.3$, $123.5,120.1,118.2,118.0,116.9,64.9,64.7,54.4,36.3$, 14.6, 14.5. HRMS calcd for $\mathrm{C}_{28} \mathrm{H}_{24} \mathrm{NO}_{7}[\mathrm{M}-\mathrm{H}]$
486.1558, found 486.1561 .

2-(4,5-二乙氧基-9,10-葱醌-2-甲酰氨基)-4-(甲硫基) 丁酸(5bd): 黄色固体, 产率 $80 \%$. m.p. $102.0 \sim 102.5{ }^{\circ} \mathrm{C}$; $[\alpha]_{\mathrm{D}}^{25}-18.4(c \quad 0.1, \mathrm{MeOH}) ;{ }^{1} \mathrm{H}$ NMR (DMSO- $d_{6}, 400$ MHz) $\delta: 12.79(\mathrm{~s}, 1 \mathrm{H}), 9.10(\mathrm{~d}, J=7.6 \mathrm{~Hz}, 1 \mathrm{H}), 8.23(\mathrm{~s}$, $1 \mathrm{H}), 7.89(\mathrm{~s}, 1 \mathrm{H}), 7.71 \sim 7.78(\mathrm{~m}, 2 \mathrm{H}), 7.55(\mathrm{~d}, J=7.6 \mathrm{~Hz}$, $1 \mathrm{H}), 4.59$ (q, $J=8.0 \mathrm{~Hz}, 1 \mathrm{H}), 4.30$ (q, $J=7.2 \mathrm{~Hz}, 2 \mathrm{H}), 4.23$ (q, $J=7.2 \mathrm{~Hz}, 2 \mathrm{H}), 2.54 \sim 2.66(\mathrm{~m}, 2 \mathrm{H}), 2.09 \sim 2.14(\mathrm{~m}$, $2 \mathrm{H}), 2.08(\mathrm{~s}, 3 \mathrm{H}), 1.40 \sim 1.46(\mathrm{~m}, 6 \mathrm{H}) ;{ }^{13} \mathrm{C} \quad \mathrm{NMR}$ (DMSO- $\left.d_{6}, 100 \mathrm{MHz}\right) \delta: 183.0,180.6,173.2,164.9,158.1$, $158.1,138.4,134.3,134.3,134.2,125.3,123.5,120.1$, $118.2,118.1,117.0,65.0,64.7,51.8,30.1,14.6$. HRMS calcd for $\mathrm{C}_{24} \mathrm{H}_{24} \mathrm{NO}_{7} \mathrm{~S}[\mathrm{M}-\mathrm{H}]^{-}$470.1279, found 470.1282 .

2-(3,5-二丙氧基-9,10-葱醌-2-羧酰氨基)乙酸 (5ca): 黄色固体, 产率 91\%. m.p. $120.1 \sim 121.0{ }^{\circ} \mathrm{C} ;{ }^{1} \mathrm{H}$ NMR (DMSO- $\left.d_{6}, 400 \mathrm{MHz}\right) \delta: 9.22(\mathrm{t}, J=6.0 \mathrm{~Hz}, 1 \mathrm{H}), 8.17$ (s, $1 \mathrm{H}), 7.89(\mathrm{~s}, 1 \mathrm{H}), 7.69 \sim 7.75(\mathrm{~m}, 2 \mathrm{H}), 7.53(\mathrm{~d}, J=8.0 \mathrm{~Hz}$, $1 \mathrm{H}), 4.17$ (t, $J=6.4 \mathrm{~Hz}, 2 \mathrm{H}), 4.10$ (t, $J=6.4 \mathrm{~Hz}, 2 \mathrm{H}), 3.96$ $(\mathrm{d}, J=5.6 \mathrm{~Hz}, 2 \mathrm{H}), 1.75 \sim 1.87(\mathrm{~m}, 4 \mathrm{H}), 1.07$ (q, $J=7.2$ $\mathrm{Hz}, 6 \mathrm{H}$ ); ${ }^{13} \mathrm{C}$ NMR (DMSO- $\left.d_{6}, 100 \mathrm{MHz}\right) \delta: 183.0,180.6$, $171.1,164.7,158.3,158.3,138.3,134.3,134.3,134.1$, 125.4, 123.7, 120.1, 118.2, 117.9, 116.8, 70.7, 70.4, 41.6, 22.1, 10.3. HRMS calcd for $\mathrm{C}_{23} \mathrm{H}_{22} \mathrm{NO}_{7}[\mathrm{M}-\mathrm{H}]$ 424.1402, found 424.1397.

2-(4,5-二丙氧基-9,10-葸醌-2-甲酰氨基)-4-甲基戊 酸(5cb): 黄色固体, 产率 $94 \%$. m.p. $118.0 \sim 118.9{ }^{\circ} \mathrm{C}$; $[\alpha]_{\mathrm{D}}^{25}-2.8(c \quad 0.1, \mathrm{MeOH}) ;{ }^{1} \mathrm{H}$ NMR (DMSO- $d_{6}, 400$ MHz) $\delta$ : $9.06(\mathrm{~d}, J=3.6 \mathrm{~Hz}, 1 \mathrm{H}), 8.22(\mathrm{~d}, J=1.2 \mathrm{~Hz}, 1 \mathrm{H})$, 7.89 (d, $J=1.2 \mathrm{~Hz}, 1 \mathrm{H}), 7.75(\mathrm{t}, J=7.6 \mathrm{~Hz}, 1 \mathrm{H}), 7.71(\mathrm{dd}$, $J=1.2,7.6 \mathrm{~Hz}, 1 \mathrm{H}), 7.54(\mathrm{dd}, J=1.2,8.0 \mathrm{~Hz}, 1 \mathrm{H}), 4.48 \sim$ $4.56(\mathrm{~m}, 1 \mathrm{H}), 4.18(\mathrm{t}, J=6.4 \mathrm{~Hz}, 2 \mathrm{H}), 4.11(\mathrm{t}, J=6.4 \mathrm{~Hz}$, $2 \mathrm{H}), 1.78 \sim 1.86(\mathrm{~m}, 4 \mathrm{H}), 1.62 \sim 1.76(\mathrm{~m}, 3 \mathrm{H}), 1.08(\mathrm{q}, J=$ $7.2 \mathrm{~Hz}, 6 \mathrm{H}), 0.95(\mathrm{~d}, J=6.4 \mathrm{~Hz}, 3 \mathrm{H}), 0.91(\mathrm{~d}, J=6.4 \mathrm{~Hz}$, $3 \mathrm{H}$ ); ${ }^{13} \mathrm{C}$ NMR (DMSO- $\left.d_{6}, 100 \mathrm{MHz}\right) \delta: 183.1,180.7$, 174.0, 164.7, 158.3, 158.2, 138.4, 134.3, 134.2, 125.5, 123.7, 120.1, 118.2, 118.1, 117.0, 70.7, 70.4, 51.1, 24.6, 23.0, 22.1, 21.2, 10.4, 10.3. HRMS calcd for $\mathrm{C}_{27} \mathrm{H}_{30} \mathrm{NO}_{7}$ $[\mathrm{M}-\mathrm{H}]^{-} \quad 480.2028$, found 480.2030 .

2-(4,5-二丙氧基-9,10-葸醌-2-羧酰氨基)-3-苯基丙 酸(5cc): 黄色固体, 产率 96\%. m.p. 115.6 116.3 ${ }^{\circ} \mathrm{C}$; $[\alpha]_{\mathrm{D}}^{25}-13.0$ ( $c$ $\left.0.1, \mathrm{MeOH}\right) ;{ }^{1} \mathrm{H}$ NMR (DMSO- $d_{6}, 400$ MHz) $\delta$ : $9.14(\mathrm{~d}, J=8.4 \mathrm{~Hz}, 1 \mathrm{H}), 8.12(\mathrm{~d}, J=1.6 \mathrm{~Hz}, 1 \mathrm{H})$, $7.69 \sim 7.76(\mathrm{~m}, 3 \mathrm{H}), 7.53(\mathrm{dd}, J=1.6,8.0 \mathrm{~Hz}, 1 \mathrm{H}), 7.33(\mathrm{~d}$, $J=6.8 \mathrm{~Hz}, 2 \mathrm{H}), 7.27(\mathrm{t}, J=7.6 \mathrm{~Hz}, 2 \mathrm{H}), 7.19$ (t, $J=7.2$ 
$\mathrm{Hz}, 1 \mathrm{H}), 4.65 \sim 4.71(\mathrm{~m}, 1 \mathrm{H}), 4.15(\mathrm{t}, J=6.4 \mathrm{~Hz}, 2 \mathrm{H}), 4.10$ (t, $J=6.4 \mathrm{~Hz}, 2 \mathrm{H}), 3.25$ (dd, $J=4.4,14 \mathrm{~Hz}, 1 \mathrm{H}), 3.11$ (q, $J=10.8 \mathrm{~Hz}, 1 \mathrm{H}), 1.75 \sim 1.86$ (m, 4H), 1.09 (d, $J=7.6 \mathrm{~Hz}$, $3 \mathrm{H}$ ), $1.06(\mathrm{~d}, J=7.2 \mathrm{~Hz}, 3 \mathrm{H}) ;{ }^{13} \mathrm{C}$ NMR (DMSO- $d_{6}, 100$ MHz) $\delta$ : 183.0, 180.6, 173.0, 164.6, 158.3, 158.2, 138.4, $138.1,134.3,134.1,129.1,128.2,126.4,125.5,123.6$, 120.1, 118.1, 118.0, 116.9, 70.6, 70.4, 54.5, 36.3, 22.1, 22.0, 10.3. HRMS calcd for $\mathrm{C}_{30} \mathrm{H}_{28} \mathrm{NO}_{7}[\mathrm{M}-\mathrm{H}]^{-}$ 514.1871, found 514.1873.

2-(3,5-二丙氧基-9,10-葱醌-2-羧酰氨基)-4-(甲硫基) 丁酸(5cd): 黄色固体, 产率 63\%. m.p. 96.3 97.3 ${ }^{\circ} \mathrm{C}$; $[\alpha]_{\mathrm{D}}^{25}-19.6(c \quad 0.1, \mathrm{MeOH}) ;{ }^{1} \mathrm{H}$ NMR (DMSO- $d_{6}, 400$ MHz) $\delta$ : $9.08(\mathrm{~d}, J=7.6 \mathrm{~Hz}, 1 \mathrm{H}), 8.22(\mathrm{~d}, J=1.6 \mathrm{~Hz}, 1 \mathrm{H})$, 7.89 (d, $J=1.2 \mathrm{~Hz}, 1 \mathrm{H}), 7.75$ (t, $J=7.6 \mathrm{~Hz}, 1 \mathrm{H}), 7.71$ (dd, $J=1.2,7.6 \mathrm{~Hz}, 1 \mathrm{H}), 7.55(\mathrm{dd}, J=1.2,8.0 \mathrm{~Hz}, 1 \mathrm{H}), 4.55 \sim$ $4.61(\mathrm{~m}, 1 \mathrm{H}), 4.18(\mathrm{t}, J=6.4 \mathrm{~Hz}, 2 \mathrm{H}), 4.11(\mathrm{t}, J=6.4 \mathrm{~Hz}$, $2 \mathrm{H}), 2.54 \sim 2.64(\mathrm{~m}, 2 \mathrm{H}), 2.09 \sim 2.14(\mathrm{~m}, 2 \mathrm{H}), 2.08(\mathrm{~s}$, $3 \mathrm{H}), 1.76 \sim 1.87(\mathrm{~m}, 4 \mathrm{H}), 1.10(\mathrm{~d}, J=7.2 \mathrm{~Hz}, 3 \mathrm{H}), 1.06$ (d, $J=7.6 \mathrm{~Hz}, 3 \mathrm{H}$ ); ${ }^{13} \mathrm{C}$ NMR (DMSO- $\left.d_{6}, 100 \mathrm{MHz}\right) \delta: 183.1$, $180.7,173.2,164.9,158.3,158.2,138.4,134.3,134.2$, $125.5,123.7,120.1,118.2,118.1,117.0,70.7,70.4,51.9$, $30.1,22.1,14.6,10.4,10.3$. HRMS calcd for $\mathrm{C}_{26} \mathrm{H}_{28} \mathrm{NO}_{7} \mathrm{~S}$ $[\mathrm{M}-\mathrm{H}]^{-}$498.1592, found 498.1595 .

2-(4,5-二丁氧基-9,10-葸醌-2-羒酰氨基)乙酸 $(\mathbf{5 d a})$ : 黄色固体, 产率 $73 \%$. m.p. $167.8 \sim 168.7{ }^{\circ} \mathrm{C} ;{ }^{1} \mathrm{H}$ NMR (DMSO- $\left.d_{6}, 400 \mathrm{MHz}\right) \delta$ : 9.27 (t, $\left.J=6.0 \mathrm{~Hz}, 1 \mathrm{H}\right), 8.17$ (dd, $J=1.2,6.0 \mathrm{~Hz}, 1 \mathrm{H}), 7.89$ (dd, $J=1.2,7.2 \mathrm{~Hz}, 1 \mathrm{H}), 7.67 \sim$ $7.75(\mathrm{~m}, 2 \mathrm{H}), 7.53(\mathrm{dd}, J=1.2,7.6 \mathrm{~Hz}, 1 \mathrm{H}), 4.20$ (t, $J=6.4$ $\mathrm{Hz}, 2 \mathrm{H}), 4.14$ (t, $J=6.4 \mathrm{~Hz}, 2 \mathrm{H}), 4.00(\mathrm{~d}, J=6.0 \mathrm{~Hz}, 2 \mathrm{H})$, $1.73 \sim 1.82(\mathrm{~m}, 4 \mathrm{H}), 1.52 \sim 1.63(\mathrm{~m}, 4 \mathrm{H}), 0.96 \sim 1.00(\mathrm{~m}$, $6 \mathrm{H}$ ); ${ }^{13} \mathrm{C}$ NMR (DMSO- $\left.d_{6}, 100 \mathrm{MHz}\right) \delta: 183.0,180.6$, 171.0, 164.8, 158.3, 158.2, 138.2, 134.3, 134.2, 134.1, 125.6, 123.8, 120.1, 118.1, 117.9, 116.8, 68.9, 68.7, 41.4, 40.2, 39.9, 39.7, 39.5, 39.3, 39.1, 38.9, 30.7, 18.6, 13.7. HRMS calcd for $\mathrm{C}_{25} \mathrm{H}_{26} \mathrm{NO}_{7}[\mathrm{M}-\mathrm{H}]^{-} 452.1715$, found 452.1710 .

2-(4,5-二丁氧基-9,10-葸醌-2-甲酰氨基)-4-甲基戊 酸(5db): 黄色固体, 产率 $89 \%$. m.p. $73.5 \sim 74.1{ }^{\circ} \mathrm{C}$; $[\alpha]_{\mathrm{D}}^{25}-3.1$ (c $\left.0.1, \mathrm{MeOH}\right) ;{ }^{1} \mathrm{H}$ NMR (DMSO- $d_{6}, 400$ MHz) $\delta$ : $9.06(\mathrm{~d}, J=8.0 \mathrm{~Hz}, 1 \mathrm{H}), 8.22(\mathrm{~d}, J=1.6 \mathrm{~Hz}, 1 \mathrm{H})$, $7.89(\mathrm{~d}, J=1.2 \mathrm{~Hz}, 1 \mathrm{H}), 7.74(\mathrm{t}, J=8.0 \mathrm{~Hz}, 1 \mathrm{H}), 7.70$ (dd, $J=1.6,8.0 \mathrm{~Hz}, 1 \mathrm{H}), 7.54(\mathrm{dd}, J=1.6,8.0 \mathrm{~Hz}, 1 \mathrm{H}), 4.49 \sim$ $4.55(\mathrm{~m}, 1 \mathrm{H}), 4.21(\mathrm{t}, J=6.4 \mathrm{~Hz}, 2 \mathrm{H}), 4.14(\mathrm{t}, J=6.4 \mathrm{~Hz}$, $2 \mathrm{H}), 1.73 \sim 1.85(\mathrm{~m}, 6 \mathrm{H}), 1.65 \sim 1.69(\mathrm{~m}, 1 \mathrm{H}), 1.54 \sim 1.61$ (m, $4 \mathrm{H}), 0.95 \sim 1.00(\mathrm{~m}, 9 \mathrm{H}), 0.91(\mathrm{~d}, J=6.0 \mathrm{~Hz}, 3 \mathrm{H}) ;{ }^{13} \mathrm{C}$
NMR (DMSO- $\left.d_{6}, 100 \mathrm{MHz}\right) \delta: 183.1,180.7,173.9,164.8$, $158.2,158.2,138.4,134.2,134.1,125.6,123.8,120.1$, $118.2,118.1,117.0,68.9,68.7,51.1,30.8,24.6,22.9,21.2$, 18.7, 13.7. HRMS calcd for $\mathrm{C}_{29} \mathrm{H}_{34} \mathrm{NO}_{7}[\mathrm{M}-\mathrm{H}]^{-}$ 508.2341, found 508.2343.

2-(4,5-二丁氧基-9,10-葱醌-2-羧酰氨基)-3-苯基丙 酸(5dc): 黄色固体, 产率 $93 \%$. m.p. $156.3 \sim 157.2{ }^{\circ} \mathrm{C}$; $[\alpha]_{\mathrm{D}}^{25}-46.1$ ( c $\left.0.1, \mathrm{MeOH}\right) ;{ }^{1} \mathrm{H}$ NMR (DMSO- $d_{6}, 400$ MHz) $\delta$ : $9.11(\mathrm{~d}, J=8.0 \mathrm{~Hz}, 1 \mathrm{H}), 8.10(\mathrm{~d}, J=1.2 \mathrm{~Hz}, 1 \mathrm{H})$, $7.68 \sim 7.76(\mathrm{~m}, 3 \mathrm{H}), 7.53(\mathrm{dd}, J=1.2,8.0 \mathrm{~Hz}, 1 \mathrm{H}), 7.33(\mathrm{~d}$, $J=7.2 \mathrm{~Hz}, 2 \mathrm{H}), 7.27$ (t, $J=7.6 \mathrm{~Hz}, 2 \mathrm{H}), 7.18$ (t, $J=7.6$ $\mathrm{Hz}, 1 \mathrm{H}), 4.64 \sim 4.69(\mathrm{~m}, 1 \mathrm{H}), 4.18(\mathrm{t}, J=6.4 \mathrm{~Hz}, 2 \mathrm{H}), 4.13$ (t, $J=6.4 \mathrm{~Hz}, 2 \mathrm{H}), 3.25(\mathrm{dd}, J=4.4,15.6 \mathrm{~Hz}, 1 \mathrm{H}), 3.10$ (q, $J=10.8 \mathrm{~Hz}, 1 \mathrm{H}), 1.72 \sim 1.82(\mathrm{~m}, 4 \mathrm{H}), 1.51 \sim 1.62(\mathrm{~m}, 4 \mathrm{H})$, $0.95 \sim 1.00(\mathrm{~m}, 6 \mathrm{H}) ;{ }^{13} \mathrm{C}$ NMR (DMSO- $\left.d_{6}, 100 \mathrm{MHz}\right) \delta$ : $183.0,180.6,173.1,164.6,158.2,158.1,138.5,138.3$, $134.2,134.1,129.1,128.2,126.3,125.5,123.7,120.1$, 118.1, 118.0, 116.8, 68.9, 68.7, 54.7, 36.4, 30.7, 30.7, 18.7, 13.7. HRMS calcd for $\mathrm{C}_{32} \mathrm{H}_{32} \mathrm{NO}_{7}[\mathrm{M}-\mathrm{H}]^{-}$542.2184, found 542.2185 .

2-(4,5-二丁氧基-9,10-葱醌-2-甲酰氨基-4-甲硫基) 丁酸(5dd): 黄色固体, 产率 $92 \%$. m.p. $147.0 \sim 147.9{ }^{\circ} \mathrm{C}$; $[\alpha]_{\mathrm{D}}^{25}-19.1$ ( $c$ $\left.0.1, \mathrm{MeOH}\right) ;{ }^{1} \mathrm{H}$ NMR (DMSO- $d_{6}, 400$ MHz) $\delta$ : $9.09(\mathrm{~d}, J=7.6 \mathrm{~Hz}, 1 \mathrm{H}), 8.21(\mathrm{~d}, J=0.8 \mathrm{~Hz}, 1 \mathrm{H})$, 7.89 (s, 1H), 7.75 (t, $J=7.6 \mathrm{~Hz}, 1 \mathrm{H}), 7.71$ (dd, $J=1.2,7.6$ $\mathrm{Hz}, 1 \mathrm{H}), 7.55(\mathrm{dd}, J=0.8,8.0 \mathrm{~Hz}, 1 \mathrm{H}), 4.56 \sim 4.61(\mathrm{~m}$, $1 \mathrm{H}), 4.21(\mathrm{t}, J=6.4 \mathrm{~Hz}, 2 \mathrm{H}), 4.14(\mathrm{t}, J=6.4 \mathrm{~Hz}, 2 \mathrm{H})$, $2.55 \sim 2.66(\mathrm{~m}, 2 \mathrm{H}), 2.09 \sim 2.16(\mathrm{~m}, 2 \mathrm{H}), 2.08(\mathrm{~s}, 3 \mathrm{H})$, $1.73 \sim 1.83(\mathrm{~m}, 4 \mathrm{H}), 1.52 \sim 1.63(\mathrm{~m}, 4 \mathrm{H}), 0.95 \sim 1.00(\mathrm{~m}$, $6 \mathrm{H}$ ); ${ }^{13} \mathrm{C}$ NMR (DMSO- $\left.d_{6}, 100 \mathrm{MHz}\right) \delta: 183.1,180.7$, $173.2,164.9,158.2,138.3,134.3,134.2,125.6,123.8$, $120.1,118.2,118.1,117.0,68.9,68.7,51.9,30.7,30.1$, 18.7, 14.6, 13.7. HRMS calcd for $\mathrm{C}_{28} \mathrm{H}_{32} \mathrm{NO}_{7} \mathrm{~S}[\mathrm{M}-\mathrm{H}]^{-}$ 526.1905 , found 526.1908 .

2-[4,5-双(芐氧基)-9,10-葱醌-2-羧酰氨基]乙酸(5ea): 黄色固体, 产率 $85 \%$. m.p. $152.8 \sim 153.6{ }^{\circ} \mathrm{C} ;{ }^{1} \mathrm{H}$ NMR (DMSO- $\left.d_{6}, 400 \mathrm{MHz}\right) \delta$ : $9.25(\mathrm{t}, J=5.6 \mathrm{~Hz}, 1 \mathrm{H}), 8.22(\mathrm{~d}$, $J=1.6 \mathrm{~Hz}, 1 \mathrm{H}), 8.04(\mathrm{~d}, J=1.6 \mathrm{~Hz}, 1 \mathrm{H}), 7.73 \sim 7.79(\mathrm{~m}$ $2 \mathrm{H}), 7.62 \sim 7.68(\mathrm{~m}, 5 \mathrm{H}), 7.36 \sim 7.44(\mathrm{~m}, 6 \mathrm{H}), 5.39(\mathrm{~s}$, $2 \mathrm{H}), 5.32(\mathrm{~s}, 2 \mathrm{H}), 3.98(\mathrm{~d}, J=5.6 \mathrm{~Hz}, 2 \mathrm{H}) ;{ }^{13} \mathrm{C} \mathrm{NMR}$ (DMSO- $\left.d_{6}, 100 \mathrm{MHz}\right) \delta: 182.8,180.9,171.3,164.6,157.8$, $157.7,138.5,136.8,136.7,134.4,134.4,134.2,128.5$, $128.3,128.3,127.6,127.6,127.0,126.8,126.8,125.6$, $123.8,120.5,118.7,118.4,117.2,70.4,70.1,41.7$. HRMS calcd for $\mathrm{C}_{31} \mathrm{H}_{22} \mathrm{NO}_{7}[\mathrm{M}-\mathrm{H}]^{-}$520.1402, found 520.1395. 
2-[4,5-双(芐氧基)-9,10-葱醌-2-甲酰氨基]-4-甲基戊 酸(5eb): 黄色固体, 产率 $80 \%$. m.p. $175.9 \sim 176.3{ }^{\circ} \mathrm{C}$; $[\alpha]_{\mathrm{D}}^{25}-3.1$ (c $\left.0.1, \mathrm{MeOH}\right) ;{ }^{1} \mathrm{H}$ NMR (DMSO- $d_{6}, 400$ MHz) $\delta: 8.93(\mathrm{~d}, J=7.6 \mathrm{~Hz}, 1 \mathrm{H}), 8.25(\mathrm{~d}, J=1.6 \mathrm{~Hz}, 1 \mathrm{H})$, $8.04(\mathrm{~d}, J=1.2 \mathrm{~Hz}, 1 \mathrm{H}), 7.74 \sim 7.80(\mathrm{~m}, 2 \mathrm{H}), 7.63 \sim 7.68$ (m, $5 \mathrm{H}), 7.34 \sim 7.43(\mathrm{~m}, 6 \mathrm{H}), 5.40(\mathrm{~s}, 2 \mathrm{H}), 5.34(\mathrm{~s}, 2 \mathrm{H})$, $4.46 \sim 4.52(\mathrm{~m}, 1 \mathrm{H}), 1.65 \sim 1.81(\mathrm{~m}, 3 \mathrm{H}), 0.95(\mathrm{~d}, J=6.0$ $\mathrm{Hz}, 3 \mathrm{H}), 0.91\left(\mathrm{~d}, J=6.0 \mathrm{~Hz}, 3 \mathrm{H}\right.$ ); ${ }^{13} \mathrm{C}$ NMR (DMSO- $d_{6}$, $100 \mathrm{MHz}) \delta: 182.9,180.9,164.4,157.7,157.6,138.8$, $136.8,136.7,134.4,134.3,134.2,128.3,127.6,126.9$, 126.8, 125.5, 123.9, 120.5, 118.7, 118.6, 117.4, 70.4, 70.2, 51.7, 24.6, 23.0, 21.3. HRMS calcd for $\mathrm{C}_{35} \mathrm{H}_{30} \mathrm{NO}_{7}[\mathrm{M}-$ H] ${ }^{-}$576.2028, found 576.2020.

2-[4,5-双(芐氧基)-9,10-葱醌-2-羧酰氨基]-3-苯基丙 酸(5ec): 黄色固体, 产率 $93 \%$. m.p. $159.8 \sim 160.4{ }^{\circ} \mathrm{C}$; $[\alpha]_{\mathrm{D}}^{25}-9.4$ (c $\left.0.1, \mathrm{MeOH}\right) ;{ }^{1} \mathrm{H}$ NMR (DMSO- $d_{6}, 400$ MHz) $\delta: 8.79$ (d, $J=7.2 \mathrm{~Hz}, 1 \mathrm{H}), 8.07$ (s, 1H), 7.95 (s, $1 \mathrm{H}), 7.69 \sim 7.76(\mathrm{~m}, 2 \mathrm{H}), 7.60 \sim 7.66(\mathrm{~m}, 5 \mathrm{H}), 7.33 \sim 7.42$ (m, 6H), 7.29 (d, $J=7.2 \mathrm{~Hz}, 2 \mathrm{H}), 7.20(\mathrm{t}, J=7.2 \mathrm{~Hz}, 2 \mathrm{H})$, $7.12(\mathrm{t}, J=7.2 \mathrm{~Hz}, 1 \mathrm{H}), 5.34$ (s, 2H), $5.31(\mathrm{~s}, 2 \mathrm{H}), 4.57 \sim$ $4.63(\mathrm{~m}, 1 \mathrm{H}), 3.11(\mathrm{q}, J=9.2 \mathrm{~Hz}, 2 \mathrm{H}) ;{ }^{13} \mathrm{C}$ NMR (DMSO- $\left.d_{6}, 100 \mathrm{MHz}\right) \delta: 182.6,180.7,163.9,157.6,139.4$, $139.0,136.7,136.6,134.2,134.1,129.0,128.2,127.8$, $127.5,126.8,126.7,125.8,125.3,123.8,120.5,118.6$, 117.1, 70.4, 70.2, 55.6, 37.1. HRMS calcd for $\mathrm{C}_{38} \mathrm{H}_{28} \mathrm{NO}_{7}$ $[\mathrm{M}-\mathrm{H}]^{-}$610.1871, found 610.1863.

2-[4,5-双(芐氧基)-9,10-葱醌-2-甲酰氨基]-4-(甲硫 基)丁酸(5ed): 黄色固体, 产率 90\%. m.p. 113.2 $113.7{ }^{\circ} \mathrm{C} ;[\alpha]_{\mathrm{D}}^{25}-13 \quad(c \quad 0.1, \mathrm{MeOH}) ;{ }^{1} \mathrm{H} \quad \mathrm{NMR}$ (DMSO- $\left.d_{6}, 400 \mathrm{MHz}\right) \delta: 8.98(\mathrm{~d}, J=7.6 \mathrm{~Hz}, 1 \mathrm{H}), 8.25(\mathrm{~d}$, $J=1.2 \mathrm{~Hz}, 1 \mathrm{H}), 8.03(\mathrm{~d}, J=1.2 \mathrm{~Hz}, 1 \mathrm{H}), 7.75 \sim 7.80(\mathrm{~m}$, $2 \mathrm{H}), 7.63 \sim 7.68(\mathrm{~m}, 5 \mathrm{H}), 7.35 \sim 7.43(\mathrm{~m}, 6 \mathrm{H}), 5.40(\mathrm{~s}$, $2 \mathrm{H}), 5.34(\mathrm{~s}, 2 \mathrm{H}), 4.53 \sim 4.58(\mathrm{~m}, 1 \mathrm{H}), 2.54 \sim 2.65(\mathrm{~m}$, $2 \mathrm{H}), 2.10 \sim 2.15(\mathrm{~m}, 2 \mathrm{H}), 2.07(\mathrm{~s}, 3 \mathrm{H}) ;{ }^{13} \mathrm{C}$ NMR (DMSO-d $\left.d_{6}, 100 \mathrm{MHz}\right) \delta: 182.9,180.9,173.4,164.6,157.8$, $157.7,138.7,136.8,136.7,134.4,134.3,134.2,128.3$, $127.6,127.6,126.9,126.8,125.6,123.9,120.5,118.7$, $117.4,70.4,70.2,52.3,30.5,30.2,14.6$. HRMS calcd for $\mathrm{C}_{34} \mathrm{H}_{28} \mathrm{NO}_{7} \mathrm{~S}[\mathrm{M}-\mathrm{H}]^{-}$594.1592, found 594.1588.

\section{2 .6 化合物 $\mathbf{6 a a} \sim 6 \mathrm{ed}$ 的合成}

取 $1 \mathrm{mmol} \mathbf{5 a a} \sim 5 \mathbf{e d} 、 1 \mathrm{~mol} / \mathrm{L}$ 的 $\mathrm{NaOH}$ 水溶液(1 $\mathrm{mL}$ ) 和 $5 \mathrm{~mL}$ 无水乙醇加入到 $25 \mathrm{~mL}$ 圆底烧瓶中, 室温摚 拌过夜, 反应完成后, 减压蒸馏即可得到大黄酸-氨基 酸缀合物钠盐 $\mathbf{6 a a} \sim 6 \mathrm{ed}$.

2-(4,5-二甲氧基-9,10-葸醌-2-羧酰氨基)乙酸钠 (6aa): 黄色固体. ${ }^{1} \mathrm{H}$ NMR (DMSO- $d_{6}, 400 \mathrm{MHz}$ ) $\delta: 8.91$ (t, $J=5.2 \mathrm{~Hz}, 1 \mathrm{H}), 7.95(\mathrm{dd}, J=1.6,8.0 \mathrm{~Hz}, 2 \mathrm{H}), 7.70(\mathrm{t}$, $J=8.0 \mathrm{~Hz}, 1 \mathrm{H}), 7.58(\mathrm{dd}, J=1.2,8.0 \mathrm{~Hz}, 1 \mathrm{H}), 7.52(\mathrm{dd}$, $J=1.2,8.0 \mathrm{~Hz}, 1 \mathrm{H}), 3.94(\mathrm{~s}, 3 \mathrm{H}), 3.93$ (s, 3H), 3.58 (d, $J=$ $5.2 \mathrm{~Hz}, 2 \mathrm{H})$.

2-(4,5-二甲氧基-9,10-葱醌-2-甲酰氨基)-4-甲基戊 酸钠(6ab): 黄色固体. ${ }^{1} \mathrm{H}$ NMR (DMSO- $d_{6}, 400 \mathrm{MHz}$, $\left.40{ }^{\circ} \mathrm{C}\right) \delta: 8.36(\mathrm{~d}, J=7.6 \mathrm{~Hz}, 1 \mathrm{H}), 8.04(\mathrm{~d}, J=1.6 \mathrm{~Hz}$, $1 \mathrm{H}), 7.88(\mathrm{~d}, J=1.6 \mathrm{~Hz}, 1 \mathrm{H}), 7.76(\mathrm{t}, J=8.0 \mathrm{~Hz}, 1 \mathrm{H}), 7.69$ (dd, $J=1.2,7.6 \mathrm{~Hz}, 1 \mathrm{H}), 7.56(\mathrm{dd}, J=1.2,8.4 \mathrm{~Hz}, 1 \mathrm{H})$, $4.11 \sim 4.15$ (m, $1 \mathrm{H}), 3.98$ (s, 3H), 3.93 (s, $3 \mathrm{H}), 1.54 \sim 1.75$ (m, 3H), $0.87 \sim 0.92(\mathrm{~m}, 6 \mathrm{H})$.

2-(4,5-二甲氧基-9,10-葱醌-2-羧酰氨基)-3-苯基丙 酸钠(6ac): 黄色固体. ${ }^{1} \mathrm{H}$ NMR (DMSO- $d_{6}, 400 \mathrm{MHz}$, $\left.40{ }^{\circ} \mathrm{C}\right) \delta: 8.43(\mathrm{~d}, J=6.8 \mathrm{~Hz}, 1 \mathrm{H}), 7.86(\mathrm{~d}, J=1.6 \mathrm{~Hz}$, 1H), 7.80 (d, $J=1.2 \mathrm{~Hz}, 1 \mathrm{H}), 7.30$ (t, $J=8.0 \mathrm{~Hz}, 1 \mathrm{H}), 7.63$ $(\mathrm{d}, J=7.6 \mathrm{~Hz}, 1 \mathrm{H}), 7.52(\mathrm{~d}, J=8.0 \mathrm{~Hz}, 1 \mathrm{H}), 7.23(\mathrm{~d}, J=$ $6.8 \mathrm{~Hz}, 2 \mathrm{H}), 7.17(\mathrm{t}, J=7.2 \mathrm{~Hz}, 2 \mathrm{H}), 7.07 \sim 7.11(\mathrm{~m}, 1 \mathrm{H})$, $4.24 \sim 4.28(\mathrm{~m}, 1 \mathrm{H}), 3.95(\mathrm{~s}, 3 \mathrm{H}), 3.92(\mathrm{~s}, 3 \mathrm{H}), 3.23(\mathrm{~d}, J=$ $4.4 \mathrm{~Hz}, 1 \mathrm{H}), 3.08$ (dd, $J=7.2,13.2 \mathrm{~Hz}, 1 \mathrm{H})$.

2-(4,5-二甲氧基-9,10-葱醌-2-甲酰氨基)-4-(甲硫基) 丁酸钠(6ad): 黄色固体. ${ }^{1} \mathrm{H}$ NMR (DMSO- $d_{6}, 400 \mathrm{MHz}$, $\left.40{ }^{\circ} \mathrm{C}\right) \delta: 8.47(\mathrm{~d}, J=6.8 \mathrm{~Hz}, 1 \mathrm{H}), 8.01(\mathrm{~d}, J=1.2 \mathrm{~Hz}$, 1H), $7.88(\mathrm{~d}, J=1.2 \mathrm{~Hz}, 1 \mathrm{H}), 7.75(\mathrm{t}, J=8.0 \mathrm{~Hz}, 1 \mathrm{H}), 7.67$ (d, $J=7.2 \mathrm{~Hz}, 1 \mathrm{H}), 7.54(\mathrm{~d}, J=8.4 \mathrm{~Hz}, 1 \mathrm{H}), 4.08 \sim 4.13$ (m, 1H), $3.98(\mathrm{~s}, 3 \mathrm{H}), 3.93(\mathrm{~s}, 3 \mathrm{H}), 2.44 \sim 2.57(\mathrm{~m}, 2 \mathrm{H})$, $1.93 \sim 2.12(\mathrm{~m}, 2 \mathrm{H}), 2.00(\mathrm{~s}, 3 \mathrm{H})$.

2-(4,5-二乙氧基-9,10-葱醌-2-羧酰氨基) 乙酸钠 (6ba): 黄色固体. ${ }^{1} \mathrm{H}$ NMR (DMSO- $\left.d_{6}, 400 \mathrm{MHz}\right) \delta: 8.65$ (t, $J=4.8 \mathrm{~Hz}, 1 \mathrm{H}), 8.01(\mathrm{~d}, J=1.6 \mathrm{~Hz}, 1 \mathrm{H}), 7.90(\mathrm{~d}, J=1.2$ $\mathrm{Hz}, 1 \mathrm{H}), 7.72(\mathrm{t}, J=8.0 \mathrm{~Hz}, 1 \mathrm{H}), 7.64(\mathrm{~d}, J=8.0 \mathrm{~Hz}, 1 \mathrm{H})$, $7.53(\mathrm{~d}, J=8.0 \mathrm{~Hz}, 1 \mathrm{H}), 4.20-4.29(\mathrm{~m}, 4 \mathrm{H}), 3.57$ (d, $J=4.8$ $\mathrm{Hz}, 2 \mathrm{H}), 1.41 \sim 1.44(\mathrm{~m}, 6 \mathrm{H})$.

2-(4,5-二乙氧基-9,10-葸醌-2-甲酰氨基)-4-甲基戊 酸钠(6bb): 黄色固体. ${ }^{1} \mathrm{H}$ NMR (DMSO- $d_{6}, 400 \mathrm{MHz}$, $\left.30{ }^{\circ} \mathrm{C}\right) \delta: 8.39(\mathrm{~d}, J=7.6 \mathrm{~Hz}, 1 \mathrm{H}), 8.04(\mathrm{~s}, 1 \mathrm{H}), 7.88(\mathrm{~s}$, 1H), $7.73(\mathrm{t}, J=8.0 \mathrm{~Hz}, 1 \mathrm{H}), 7.68(\mathrm{~d}, J=6.8 \mathrm{~Hz}, 1 \mathrm{H}), 7.53$ $(\mathrm{d}, J=8.0 \mathrm{~Hz}, 1 \mathrm{H}), 4.27(\mathrm{q}, J=6.8 \mathrm{~Hz}, 2 \mathrm{H}), 4.22(\mathrm{q}, J=$ $6.8 \mathrm{~Hz}, 2 \mathrm{H}), 4.11-4.16(\mathrm{~m}, 1 \mathrm{H}), 1.55 \sim 1.72(\mathrm{~m}, 3 \mathrm{H}), 1.42$ (q, $J=6.8 \mathrm{~Hz}, 6 \mathrm{H}), 0.88 \sim 0.90(\mathrm{~m}, 6 \mathrm{H})$.

2-(4,5-二乙氧基-9,10-葸醌-2-羧酰氨基)-3-苯基丙 酸钠(6bc): 黄色固体. ${ }^{1} \mathrm{H}$ NMR (DMSO- $d_{6}, 400 \mathrm{MHz}$, $\left.40{ }^{\circ} \mathrm{C}\right) \delta: 8.25(\mathrm{~d}, J=6.8 \mathrm{~Hz}, 1 \mathrm{H}), 7.88(\mathrm{~d}, \mathrm{~J}=1.6 \mathrm{~Hz}, 1 \mathrm{H})$, $7.66 \sim 7.43(\mathrm{~m}, 3 \mathrm{H}), 7.52(\mathrm{~d}, J=8.0 \mathrm{~Hz}, 1 \mathrm{H}), 7.15 \sim 7.22$ (m, 4H), 7.10 (t, $J=7.2 \mathrm{~Hz}, 1 \mathrm{H}), 4.20 \sim 4.29(\mathrm{~m}, 5 \mathrm{H}), 3.22$ 
$(\mathrm{d}, J=4.8 \mathrm{~Hz}, 1 \mathrm{H}), 3.07(\mathrm{dd}, J=6.8,13.2 \mathrm{~Hz}, 1 \mathrm{H}), 1.40 \sim$ $1.44(\mathrm{~m}, 6 \mathrm{H})$.

2-(4,5-二乙氧基-9,10-蒽醌-2-甲酰氨基)-4-(甲硫基) 丁酸钠 $(6 \mathbf{b d})$ : 黄色固体. ${ }^{1} \mathrm{H}$ NMR $\left(\mathrm{DMSO}-d_{6}, 400 \mathrm{MHz}\right.$, $\left.30{ }^{\circ} \mathrm{C}\right) \delta: 8.46(\mathrm{~d}, J=6.8 \mathrm{~Hz}, 1 \mathrm{H}), 8.02(\mathrm{~d}, J=1.2 \mathrm{~Hz}$, $1 \mathrm{H}), 7.86$ (d, $J=1.2 \mathrm{~Hz}, 1 \mathrm{H}), 7.73$ (t, $J=8.0 \mathrm{~Hz}, 1 \mathrm{H}), 7.67$ (dd, $J=1.2,7.6 \mathrm{~Hz}, 1 \mathrm{H}), 7.53(\mathrm{dd}, J=5.2,8.4 \mathrm{~Hz}, 1 \mathrm{H})$, 4.28 (q, $J=6.8 \mathrm{~Hz}, 2 \mathrm{H}), 4.22$ (q, $J=6.8 \mathrm{~Hz}, 2 \mathrm{H}), 4.07 \sim$ $4.11(\mathrm{~m}, 1 \mathrm{H}), 2.42 \sim 2.48(\mathrm{~m}, 2 \mathrm{H}), 1.93 \sim 2.12(\mathrm{~m}, 2 \mathrm{H})$, $2.02(\mathrm{~s}, 3 \mathrm{H}), 1.40 \sim 1.45(\mathrm{~m}, 6 \mathrm{H})$.

2-(3,5-二丙氧基-9,10-葱醌-2-羧酰氨基) 乙酸钠 (6ca): 黄色固体. ${ }^{1} \mathrm{H}$ NMR (DMSO- $d_{6}, 400 \mathrm{MHz}, 40{ }^{\circ} \mathrm{C}$ ) $\delta: 8.32(\mathrm{t}, J=4.8 \mathrm{~Hz}, 1 \mathrm{H}), 8.04(\mathrm{~d}, J=1.2 \mathrm{~Hz}, 1 \mathrm{H}), 7.86$ $(\mathrm{d}, J=1.6 \mathrm{~Hz}, 1 \mathrm{H}), 7.73(\mathrm{t}, J=8.0 \mathrm{~Hz}, 1 \mathrm{H}), 7.68$ (dd, $J=$ $1.2,7.2 \mathrm{~Hz}, 1 \mathrm{H}), 7.53(\mathrm{dd}, J=1.2,8.0 \mathrm{~Hz}, 1 \mathrm{H}), 4.17(\mathrm{t}, J=$ $6.4 \mathrm{~Hz}, 2 \mathrm{H}), 4.11(\mathrm{t}, J=6.4 \mathrm{~Hz}, 2 \mathrm{H}), 3.55(\mathrm{~d}, J=6.4 \mathrm{~Hz}$, $2 \mathrm{H}), 1.78 \sim 1.85(\mathrm{~m}, 4 \mathrm{H}), 1.06 \sim 1.10(\mathrm{~m}, 6 \mathrm{H})$.

2-(4,5-二丙氧基-9,10-蒽醌-2-甲酰氨基)-4-甲基戊 酸钠 $(6 \mathbf{c b})$ : 黄色固体. ${ }^{1} \mathrm{H}$ NMR (DMSO- $d_{6}, 400 \mathrm{MHz}$, $\left.30{ }^{\circ} \mathrm{C}\right) \delta: 8.39(\mathrm{~d}, J=8.0 \mathrm{~Hz}, 1 \mathrm{H}), 8.05(\mathrm{~s}, 1 \mathrm{H}), 7.87$ (s, $1 \mathrm{H}), 7.72$ (t, $J=8.0 \mathrm{~Hz}, 1 \mathrm{H}), 7.67$ (d, $J=6.8 \mathrm{~Hz}, 1 \mathrm{H}), 7.52$ $(\mathrm{d}, J=8.0 \mathrm{~Hz}, 1 \mathrm{H}), 4.15 \sim 4.17(\mathrm{~m}, 3 \mathrm{H}), 4.10(\mathrm{t}, J=6.0$ $\mathrm{Hz}, 2 \mathrm{H}), 1.77 \sim 1.83(\mathrm{~m}, 4 \mathrm{H}), 1.56 \sim 1.68(\mathrm{~m}, 3 \mathrm{H}), 1.05 \sim$ $1.09(\mathrm{~m}, 6 \mathrm{H}), 0.88 \sim 0.90(\mathrm{~m}, 6 \mathrm{H})$.

2-(4,5-二丙氧基-9,10-蒽醌-2-羧酰氨基)-3-苯基丙 酸钠(6cc): 黄色固体. ${ }^{1} \mathrm{H}$ NMR (DMSO- $\left.d_{6}, 400 \mathrm{MHz}\right) \delta$ : $8.35(\mathrm{~d}, J=6.4 \mathrm{~Hz}, 1 \mathrm{H}), 7.87(\mathrm{~s}, 1 \mathrm{H}), 7.75(\mathrm{~s}, 1 \mathrm{H}), 7.71(\mathrm{t}$, $\mathrm{J}=8.0 \mathrm{~Hz}, 1 \mathrm{H}), 7.64(\mathrm{~d}, J=7.2 \mathrm{~Hz}, 1 \mathrm{H}), 7.52(\mathrm{~d}, J=7.2$ $\mathrm{Hz}, 1 \mathrm{H}), 7.15 \sim 7.21(\mathrm{~m}, 4 \mathrm{H}), 7.09(\mathrm{t}, J=7.2 \mathrm{~Hz}, 1 \mathrm{H}), 4.22$ $(\mathrm{q}, J=7.2 \mathrm{~Hz}, 1 \mathrm{H}), 4.08 \sim 4.15(\mathrm{~m}, 4 \mathrm{H}), 3.22(\mathrm{dd}, J=4.4$, $13.2 \mathrm{~Hz}, 1 \mathrm{H}), 3.05(\mathrm{dd}, J=7.2,13.2 \mathrm{~Hz}, 1 \mathrm{H}), 1.77 \sim 1.83$ $(\mathrm{m}, 4 \mathrm{H}), 1.04 \sim 1.09(\mathrm{~m}, 6 \mathrm{H})$.

2-(3,5-二丙氧基-9,10-葱醌-2-羧酰氨基)-4-(甲硫基) 丁酸钠(6cd): 黄色固体. ${ }^{1} \mathrm{H}$ NMR (DMSO- $d_{6}, 400 \mathrm{MHz}$, $\left.40{ }^{\circ} \mathrm{C}\right) \delta: 8.38(\mathrm{~d}, J=6.8 \mathrm{~Hz}, 0.5 \mathrm{H}), 8.32(\mathrm{~d}, J=6.8 \mathrm{~Hz}$, $0.5 \mathrm{H}), 8.03 \sim 8.04(\mathrm{~m}, 1 \mathrm{H}), 7.84 \sim 7.86(\mathrm{~m}, 1 \mathrm{H}), 7.70 \sim$ $7.76(\mathrm{~m}, 2 \mathrm{H}), 7.54(\mathrm{dd}, J=1.6,7.6 \mathrm{~Hz}, 1 \mathrm{H}), 4.18(\mathrm{t}, J=6.4$ $\mathrm{Hz}, 2 \mathrm{H}), 4.12(\mathrm{t}, J=6.4 \mathrm{~Hz}, 2 \mathrm{H}), 4.02 \sim 4.07(\mathrm{~m}, 1 \mathrm{H})$, $2.71 \sim 2.88(\mathrm{~m}, 2 \mathrm{H}), 2.10 \sim 2.43(\mathrm{~m}, 2 \mathrm{H}), 2.02(\mathrm{~s}, 3 \mathrm{H})$, $1.78 \sim 1.85(\mathrm{~m}, 4 \mathrm{H}), 1.06 \sim 1.10(\mathrm{~m}, 6 \mathrm{H})$.

2-(4,5-二丁氧基-9,10-葱醌-2-羧酰氨基) 乙酸钠 (6da): 黄色固体. ${ }^{1} \mathrm{H}$ NMR (DMSO- $d_{6}, 400 \mathrm{MHz}, 40{ }^{\circ} \mathrm{C}$ ) $\delta$ : $8.37(\mathrm{t}, J=4.8 \mathrm{~Hz}, 1 \mathrm{H}), 8.03(\mathrm{~d}, J=1.6 \mathrm{~Hz}, 1 \mathrm{H}), 7.86$ $(\mathrm{d}, J=1.6 \mathrm{~Hz}, 1 \mathrm{H}), 7.72(\mathrm{t}, J=8.0 \mathrm{~Hz}, 1 \mathrm{H}), 7.67(\mathrm{dd}, J=$ $1.2,8.0 \mathrm{~Hz}, 1 \mathrm{H}), 7.52$ (dd, $J=1.2,8.0, \mathrm{~Hz}, 1 \mathrm{H}), 4.20$ (t,
$J=6.4 \mathrm{~Hz}, 2 \mathrm{H}), 4.14(\mathrm{t}, J=6.4 \mathrm{~Hz}, 2 \mathrm{H}), 3.56(\mathrm{~d}, J=4.8$ $\mathrm{Hz}, 2 \mathrm{H}), 1.74 \sim 1.82(\mathrm{~m}, 4 \mathrm{H}), 1.52 \sim 1.62(\mathrm{~m}, 4 \mathrm{H}), 0.98(\mathrm{t}$, $J=7.2 \mathrm{~Hz}, 3 \mathrm{H}), 0.97$ (t, $J=7.2 \mathrm{~Hz}, 3 \mathrm{H})$.

2-(4,5-二丁氧基-9,10-蒽醌-2-甲酰氨基)-4-甲基戊 酸钠 $(6 \mathbf{d b})$ : 黄色固体. ${ }^{1} \mathrm{H}$ NMR (DMSO- $d_{6}, 400 \mathrm{MHz}$, $\left.30{ }^{\circ} \mathrm{C}\right) \delta: 8.38(\mathrm{~d}, J=7.6 \mathrm{~Hz}, 1 \mathrm{H}), 8.04(\mathrm{~d}, J=1.2 \mathrm{~Hz}$, 1H), 7.87 (d, $J=1.6 \mathrm{~Hz}, 1 \mathrm{H}), 7.72$ (t, $J=8.0 \mathrm{~Hz}, 1 \mathrm{H}), 7.67$ (dd, $J=1.2,7.6 \mathrm{~Hz}, 1 \mathrm{H}), 7.52(\mathrm{dd}, J=1.2,8.0 \mathrm{~Hz}, 1 \mathrm{H})$, $4.19(\mathrm{t}, J=6.0 \mathrm{~Hz}, 2 \mathrm{H}), 4.12 \sim 4.15(\mathrm{~m}, 3 \mathrm{H}), 1.75 \sim 1.79$ $(\mathrm{m}, 4 \mathrm{H}), 1.64 \sim 1.70(\mathrm{~m}, 2 \mathrm{H}), 1.53 \sim 1.59(\mathrm{~m}, 5 \mathrm{H}), 0.95 \sim$ $0.99(\mathrm{~m}, 6 \mathrm{H}), 0.88 \sim 0.90(\mathrm{~m}, 6 \mathrm{H})$.

2-(4,5-二丁氧基-9,10-葱醌-2-羧酰氨基)-3-苯基丙 酸钠 $(6 \mathbf{6 d c})$ : 黄色固体. ${ }^{1} \mathrm{H}$ NMR (DMSO- $d_{6}, 400 \mathrm{MHz}$, $\left.40{ }^{\circ} \mathrm{C}\right) \delta: 8.19(\mathrm{~d}, J=6.4 \mathrm{~Hz}, 1 \mathrm{H}), 7.88(\mathrm{~s}, 1 \mathrm{H}), 7.66 \sim$ $7.74(\mathrm{~m}, 3 \mathrm{H}), 7.52(\mathrm{~d}, J=7.6 \mathrm{~Hz}, 1 \mathrm{H}), 7.08 \sim 7.20(\mathrm{~m}$, $5 \mathrm{H}), 4.12 \sim 4.22(\mathrm{~m}, 5 \mathrm{H}), 3.22(\mathrm{~d}, \mathrm{~J}=4.8 \mathrm{~Hz}, 1 \mathrm{H}), 3.08$ $(\mathrm{dd}, J=6.4,13.2 \mathrm{~Hz}, 1 \mathrm{H}), 1.73 \sim 1.81(\mathrm{~m}, 4 \mathrm{H}), 1.53 \sim 1.59$ $(\mathrm{m}, 4 \mathrm{H}), 0.95 \sim 0.99(\mathrm{~m}, 6 \mathrm{H})$.

2-(4,5-二丁氧基-9,10-蒽醌-2-甲酰氨基-4-甲硫基) 丁酸钠(6dd): 黄色固体. ${ }^{1} \mathrm{H}$ NMR (DMSO- $d_{6}, 400 \mathrm{MHz}$, $\left.40{ }^{\circ} \mathrm{C}\right) \delta: 8.48(\mathrm{dd}, J=3.2,7.2 \mathrm{~Hz}, 1 \mathrm{H}), 8.02 \sim 8.04(\mathrm{~m}$, $1 \mathrm{H}), 7.87 \sim 7.88(\mathrm{~m}, 1 \mathrm{H}), 7.66 \sim 7.74(\mathrm{~m}, 2 \mathrm{H}), 7.52(\mathrm{~d}, J=$ $8.0 \mathrm{~Hz}, 1 \mathrm{H}), 4.09 \sim 4.22(\mathrm{~m}, 5 \mathrm{H}), 2.62 \sim 2.89(\mathrm{~m}, 2 \mathrm{H}), 2.49$ $(\mathrm{s}, 3 \mathrm{H}), 2.04 \sim 2.25(\mathrm{~m}, 2 \mathrm{H}), 1.74 \sim 1.82(\mathrm{~m}, 4 \mathrm{H}), 1.54 \sim$ $1.60(\mathrm{~m}, 4 \mathrm{H}), 0.96 \sim 1.00(\mathrm{~m}, 6 \mathrm{H})$.

2-(4,5-双(苄氧基)-9,10-葱醌-2-羧酰氨基)乙酸钠 (6ea): 黄色固体. ${ }^{1} \mathrm{H}$ NMR (DMSO- $d_{6}, 400 \mathrm{MHz}, 30{ }^{\circ} \mathrm{C}$ ) $\delta$ : $8.91(\mathrm{t}, J=5.2 \mathrm{~Hz}, 1 \mathrm{H}), 8.11(\mathrm{~d}, J=1.6 \mathrm{~Hz}, 1 \mathrm{H}), 8.02$ $(\mathrm{d}, J=1.6 \mathrm{~Hz}, 1 \mathrm{H}), 7.61 \sim 7.74(\mathrm{~m}, 7 \mathrm{H}), 7.37 \sim 7.45(\mathrm{~m}$, $6 \mathrm{H}), 5.37$ (s, 2H), 5.34 (s, 2H), 3.61 (d, J=5.2 Hz, 2H).

2-(4,5-双(芐氧基)-9,10-葱醌-2-甲酰氨基)-4-甲基戊 酸钠(6eb): 黄色固体. ${ }^{1} \mathrm{H}$ NMR (DMSO- $d_{6}, 400 \mathrm{MHz}$, $\left.40{ }^{\circ} \mathrm{C}\right) \delta: 8.51(\mathrm{~d}, J=5.2 \mathrm{~Hz}, 1 \mathrm{H}), 8.06(\mathrm{~s}, 2 \mathrm{H}), 7.63 \sim$ $7.78(\mathrm{~m}, 7 \mathrm{H}), 7.36 \sim 7.44(\mathrm{~m}, 6 \mathrm{H}), 5.40(\mathrm{~s}, 2 \mathrm{H}), 5.34(\mathrm{~s}$, $2 \mathrm{H}), 4.14 \sim 4.19(\mathrm{~m}, 1 \mathrm{H}), 1.60 \sim 1.74(\mathrm{~m}, 3 \mathrm{H}), 0.91(\mathrm{~d}, \mathrm{~J}=$ $6.0 \mathrm{~Hz}, 6 \mathrm{H})$.

2-(4,5-双(苄氧基)-9,10-葱醌-2-羧酰氨基)-3-苯基丙 酸钠(6ec): 黄色固体. ${ }^{1} \mathrm{H}$ NMR (DMSO- $d_{6}, 400 \mathrm{MHz}$, $\left.40{ }^{\circ} \mathrm{C}\right) \delta: 8.41(\mathrm{~d}, J=5.2 \mathrm{~Hz}, 1 \mathrm{H}), 7.95(\mathrm{~d}, J=1.2 \mathrm{~Hz}$, $1 \mathrm{H}), 7.90(\mathrm{~d}, J=1.2 \mathrm{~Hz}, 1 \mathrm{H}), 7.63 \sim 7.77(\mathrm{~m}, 7 \mathrm{H}), 7.36 \sim$ $7.44(\mathrm{~m}, 6 \mathrm{H}), 7.09 \sim 7.22(\mathrm{~m}, 5 \mathrm{H}), 5.37(\mathrm{~s}, 2 \mathrm{H}), 5.34(\mathrm{~s}$, $2 \mathrm{H}), 4.22 \sim 4.27(\mathrm{~m}, 1 \mathrm{H}), 3.23(\mathrm{~d}, J=4.4 \mathrm{~Hz}, 1 \mathrm{H}), 3.10$ (dd, $J=6.4,13.2 \mathrm{~Hz}, 1 \mathrm{H})$.

2-(4,5-双(茮氧基)-9,10-蒽醌-2-甲酰氨基)-4-(甲硫 基)丁酸钠(6ed): 黄色固体. ${ }^{1} \mathrm{H} \mathrm{NMR}\left(\mathrm{CD}_{3} \mathrm{OD}, 400 \mathrm{MHz}\right)$ 
$\delta: 8.26(\mathrm{~s}, 1 \mathrm{H}), 8.03(\mathrm{~s}, 1 \mathrm{H}), 7.79(\mathrm{~d}, J=7.6 \mathrm{~Hz}, 1 \mathrm{H})$, $7.65 \sim 7.69(\mathrm{~m}, 3 \mathrm{H}), 7.62(\mathrm{~d}, J=7.2 \mathrm{~Hz}, 2 \mathrm{H}), 7.52(\mathrm{~d}, J=$ $8.4 \mathrm{~Hz}, 1 \mathrm{H}), 7.32 \sim 7.41(\mathrm{~m}, 6 \mathrm{H}), 5.38(\mathrm{~s}, 2 \mathrm{H}), 5.30(\mathrm{~s}$, $2 \mathrm{H}), 4.63(\mathrm{dd}, J=4.4,7.6 \mathrm{~Hz}, 1 \mathrm{H}), 2.61 \sim 2.68(\mathrm{~m}, 2 \mathrm{H})$, $2.28 \sim 2.34(\mathrm{~m}, 1 \mathrm{H}), 2.15 \sim 2.19(\mathrm{~m}, 1 \mathrm{H}), 2.13(\mathrm{~s}, 1 \mathrm{H})$.

\section{3 体外抗肿瘤活性测试}

将细胞以约 $10^{5}$ 个 $/ \mathrm{mL}$ 的密度接种于 96 孔板, 每孔 接种 $100 \mu \mathrm{L}$, 置 $\mathrm{CO}_{2}$ 培养箱中培养至对数生长期. 然后 按预设的浓度梯度加入待测样品, 每一梯度 3 个重复. 对照组加入等体积的溶解样品用的溶剂. 培养 $48 \mathrm{~h}$ 后, 每孔加入 $20 \mu \mathrm{L}$ 的 MTT $(5 \mathrm{mg} / \mathrm{mL})$, 然后置于 $37{ }^{\circ} \mathrm{C}$ 温 育 $4 \mathrm{~h}$. 除去上清后, 每孔加入 $100 \mu \mathrm{L}$ 的 DMSO, 振荡 $10 \mathrm{~min}$ 溶解沉淀, 随后用酶标仪检测 OD 值, 波长 490 $\mathrm{nm}$. 用下式求出样品一定浓度下的细胞存活率:

存活率 $(\%)=$ 样品组平均 $\mathrm{OD}$ 值/对照组平均 $\mathrm{OD}$ 值 $\times 100 \%$

以细胞存活率对药物浓度对数作图, 按作图法求出 每个样品的 $\mathrm{IC}_{50}$ 值.

\section{4 化合物与 DNA 相互作用的荧光光谱研究}

用 $\mathrm{pH} 7.4$ 的 Tris-HCl 缓冲溶液配制化合物的待测溶 液, 浓度为 $1 \times 10^{-5} \mathrm{~mol} / \mathrm{L}$, 向此化合物中加入不同体积 的 ct-DNA 溶液，使 DNA 浓度分别为 $0 、 8 、 16 、 24$ 、 32 和 $40 \mu \mathrm{mol} / \mathrm{L}$, 在激发波长为 $260 \mathrm{~nm}$ 时, 依次测试溶 液的荧光发射光谱, 得到化合物与 DNA 相互作用的苂 光光谱图.

\section{辅助材料(Supporting Information) 化合物 4aa 4ed} 的 ${ }^{1} \mathrm{H}$ NMR 谱图, 5aa 5ed 的 ${ }^{1} \mathrm{H}$ NMR 和 ${ }^{13} \mathrm{C}$ NMR 谱 图, 以及 $6 \mathrm{aa} \sim 6 \mathrm{ed}$ 的 ${ }^{1} \mathrm{H}$ NMR 谱图. 这些材料可以免费 从本刊网站(http://sioc-journal.cn/)上下载.

\section{References}

[1] Ferlay, J.; Soerjomataram, I.; Dikshit, R.; Eser, S.; Mathers, C.; Rebelo, M.; Parkin, D. M.; Forman, D.; Bray, F. Int. J. Cancer 2015, 136, E359.

[2] Newman, D. J.; Cragg, G. M. J. Nat. Prod. 2007, 70, 461.

[3] Liu, X.; Cheng, J.; Zheng, X. C.; Chen, Y. G.; Wu, C.; Li, B.; Fu, J. F.; Cao, H. W.; Lu, Y. L.; Li, J.; Zheng, J.; Zhou, H. Int. Immunopharmacol. 2009, 9, 1021.

[4] Chung, J. G.; Tsou, M. F.; Wang, H. H.; Lo, H. H.; Hsieh, S. E.; Yen, Y. S.; Wu, L. T.; Chang, S. H.; Ho, C. C.; Hung, C. F. J. Appl. Toxicol. 1998, 18, 117.

[5] Hao, K.; Qi, Q.; Wan, P.; Zhang, J. W.; Hao, H. P.; Liang, Y.; Xie, L.; Wang, G. J.; Sun, J. G. Basic Clin. Pharmacol. Toxicol. 2014, 114,160 .
[6] Yu, L.; Xiang, H.; Fan, J. W.; Wang, D. C.; Yang, F.; Guo, N.; Jin, Q.; Deng, X. M. J. Biotechnol. 2008, 135, 304.

[7] Gao, Q.; Qin, W. S.; Jia, Z. H.; Zheng, J. M.; Zeng, C. H.; Li, L. S.; Liu, Z. H. Planta Med. 2010, 76, 27.

[8] Peng, L. L.; Yang, J. Y.; Ning, C.; Zhang, J.; Xiao, X. C.; He, D.; Wang, X. Y.; Li, Z. P.; Fu, S. S.; Ning, J. P. Biol. Pharm. Bull. 2012, 35, 1676.

[9] Yadav, A.; Bhardwaj, R.; Sharma, R. A. Res. J. Med. Plant 2013, 7, 150.

[10] Ip, S. W.; Weng, Y. S.; Lin, S. Y.; Yang, M. D.; Tang, N. Y.; Su, C. C.; Chung, J. G. Anticancer Res. 2007, 27, 379.

[11] Fernand, V. E.; Losso, J. N.; Truax, R. E.; Villar, E. E.; Bwambok, D. K.; Fakayode, S. O.; Lowry, M.; Warner, I. M. Chem. Biol. Interact. 2011, 192, 220.

[12] Badria, F. A.; Ibrahim A. S. Drug Discoveries Ther. 2013, 7, 84.

[13] Wang, Q.; Zhang, N. N.; Li, H. Y.; Jiang, M.; Gao, J.; Bai, G. Acta Pharm. Sin. 2012, 47, 1618 (in Chinese).

(王倩, 张楠楠, 李红艳, 姜民, 高洁, 白钢, 药学学报, 2012, 47, 1618.)

[14] Hsia, T. C.; Yang, J. S.; Chen, G. W.; Chiu, T. H.; Lu, H. F.; Yang, M. D.; Yu, F. S.; Liu, K. C.; Lai, K. C.; Lin, C. C.; Chung, J. G. Anticancer Res. 2009, 29, 309.

[15] Chang, C. Y.; Chan, H. L.; Lin, H. Y.; Way, T. D.; Kao, M. C.; Song, M. Z.; Lin, Y. J.; Lin, C. W. J. Evidence-Based Complementary Alterna. Med. 2012, 45, 1052

[16] Lai, W. W.; Yang, J. S.; Lai, K. C.; Kuo, C. L.; Hsu, C. K.; Wang, C. K.; Chang, C. Y.; Lin, J. J.; Tang, N. Y.; Chen, P. Y.; Huang, W. W.; Chung, J. G. In Vivo 2009, 23, 309.

[17] Gan, Y.; He, L. H.; Zhang, Y. H.; Wang, J. H.; Zhao, J. Chin. J. Org. Chem. 2014, 34, 589 (in Chinese).

(甘莹，何利华，张亚宏，王建红，赵瑾，有机化学，2014，34, 589.)

[18] Marković, V.; Debeljak, N.; Stanojković, T.; Kolundzija, B.; Sladić, D.; Vujcić, M.; Janović, B.; Tanić, N.; Perović, M.; Tesić, V.; Antić, J.; Joksović, M. D. Eur. J. Med. Chem. 2015, 89, 401.

[19] Igarashi, Y.; Trujillo, M. E.; Martínez-Molina, E.; Yanase, S.; Miyanaga, S.; Obata, T.; Sakurai, H.; Saiki, I.; Fujita, T.; Furumai, T. Bioorg. Med. Chem. Lett. 2007, 17, 3702.

[20] Barthel, B. L.; Mooz, E. L.; Wiener, L. E.; Koch, G. G.; Koch, T. H. J. Med. Chem. 2016, 59, 2205.

[21] Zhu, X.; Ye, X.; Song, L.; Luo, Y.; Tang, Q.; Jin, Y.; Li, X. Med. Chem. Res. 2013, 22, 2228.

[22] Yuan, Y.-F.; Hu, X.-Y.; He, Y.; Deng, J.-G. Nat. Prod. Commun. 2012, 7, 207.

[23] Viayna, E.; Sola, I.; Bartolini, M.; Simone, A. D.; Tapia-Rojas, C.; Serrano, F. G.; Sabaté, R.; Juárez-Jiménez, J.; Pérez, B.; Luque, F. J.; Andrisano, V.; Clos, M. V.; Inestrosa, N. C.; Muñoz-Torrero, D. J. Med. Chem. 2014, 57, 2549.

[24] Li, S.-Y.; Jiang, N.; Xie, S.-S.; Wang, X.-B.; Kong, L.-Y. Org. Biomol. Chem. 2014, 12, 801-814.

[25] Yao, G.-Y.; Ye, M.-Y.; Huang, R.-Z.; Li, Y.-J.; Pan, Y.-M.; Xu, Q.; Liao, Z.-X.; Wang, H.-S. Bioorg. Med. Chem. Lett. 2014, 24, 501.

[26] Liang Y.-K.; Yue, Z.-Z.; Li, J.-X.; Tan, C.; Miao, Z.-H.; Tan, W.-F.; Yang, C.-H. Eur. J. Med. Chem. 2014, 84, 505.

[27] Sirajuddin, M.; Ali, S.; Badshah, A. J. Photochem. Photobiol., B 2013, 124, 1 